\title{
BubBLing AND CRASHING EXCHANGE RATES
}

\author{
MARIANNA GRIMALDI \\ PAUL DE GRAUWE
}

\author{
CESIFO WORKING PAPER NO. 1045 \\ CATEGORY 6: MONETARY POLICY AND INTERNATIONAL FINANCE \\ SEPTEMBER 2003
}

An electronic version of the paper may be downloaded

- from the SSRN website: Www.SSRN.com

- from the CESifo website: www.CESifo.de 


\title{
BUBBLING AND CRASHING EXCHANGE RATES
}

\begin{abstract}
We develop a simple model of the foreign exchange market in which agents optimize their portfolio and use different forecasting rules. They check the profitability of these rules ex post and select the more profitable one.This model produces two kinds of equilibria, a fundamental and a bubble one. In a stochastic environment the model generates a complex dynamics in which bubbles and crashes occur at unpredictable moments. We also analyse the empirical relevance of the model.
\end{abstract}

JEL Code: F31, F41.

\author{
Marianna Grimaldi \\ University of Leuven \\ Naamsestraat 69 \\ 3000 Leuven \\ Belgium
}

\author{
Paul De Grauwe \\ University of Leuven \\ Naamsestraat 69 \\ 3000 Leuven \\ Belgium
}

Paul.degrauwe@econ.kuleuven.ac.be 


\section{Introduction}

Since the publication of Kindleberger's "Manias, Panics, and Crashes" in 1978, a large literature has flourished on the theory and the empirics of bubbles and crashes in financial markets. Two schools of thought can be detected. One school has developed from the contributions of Blanchard in the late '70s on rational bubbles (see Blanchard(1979), Blanchard and Watson(1982)). In this view, bubbles can occur in rational expectations (RE) models when the time of the crash is not known with certainty. It is then in the interest of rational agents to "ride the bubble" ${ }^{1}$. A second school of thought has concentrated on the non rational sources of the emergence of bubbles (herding behaviour, bandwagon effects $\left.^{2}\right)$.

Both approaches suffer from some inherent defects. The rational expectations approach has come under increasing criticism both from a theoretical and empirical point of view. The main criticism is that it assumes that individual agents are capable of storing and processing in their individual brains all the relevant information existing in the outside world; an information set which in its complexity by far surpasses the complexity of the individual brain. The response to this criticism has usually been that the rational expectations assumptions is nothing but an assumption about the model-consistency of expectations. The price for this requirement of logical consistency, however, is that in order to make it plausible that agents operating in such a model can be assumed to understand its structure, rational expectations models have to be kept exceedingly simple. As a result, the informational problems agents face in a complex environment is assumed away ${ }^{3}$. All this would not really be a problem if the rational expectations models would pass the only important scientific test which is its empirical verification. Unfortunately, the accumulated empirical evidence in the financial markets is not favourable for the rational expectations model. Too many anomalies have been detected in the financial markets contradicting the rational expectations paradigm. (See De Grauwe and Grimaldi(2003) for a discussion of these anomalies in the foreign exchange market).

Apart from this general criticism of the rational expectations model, the Blanchard-Watson rational bubble model can be criticised for the fact that it predicts the occurrence of bubbles whose features are not found in empirical evidence (e.g. exponentially distributed bubbles, symmetry between bubble and crash phases, see Mandelbrot(1997) and Lux and Sornette (2002)).

\footnotetext{
${ }^{1}$ There is of course a strong "negationist" tradition in the ratioanl expectations literature which denies the existence of bubbles and crashes. In a rational expectations efficient market world bubbles and crashes are meaningless concepts, since the exchange rate always reflects the changing and often volatile information on underlying fundamental variables. A well-known proponent of this view is Garber(2000).

${ }^{2}$ For a recent insightful analysis see Shiller(2000). There is also a strong tradition in the behavioural finance literature analysing anomalies in the financial markets that can trigger bubbles and crashes. See Schleiffer(2000) and Thaler(1994).

${ }^{3} \mathrm{~A}$ recent booming literature tries to deal with this problem by introducing adaptive learning. This literature has led to important new insights. For interesting contributions introducing least squares learning see Evans and Honkapohja(2001).
} 
The second approach, focusing on the irrationality of agents, provides a wealth of insights in the complexity of human behaviour. The problem it faces, however, is that it has to make as many special assumptions about human behaviour as the number of phenomena it wishes to explain. As a result, it has not yet developed into a scientific alternative for explaining bubbles and crashes in the financial markets.

The aim of this paper is to suggest a possible third alternative for understanding why bubbles and crashes occur in the foreign exchange markets. We develop a simple model of the exchange rate in which we relax the RE hyphotesis. We assume that individual agents are not capable of using all available information in the model, and that they select different simple forecasting rules. Although agents have potentially access to the same kind of information they differ in the interpretation and in the use of such information ${ }^{4}$.

We assume two kinds of agents, fundamentalists who use fundamental information and technical traders (chartists) who extrapolate past exchange rate changes. Empirical evidence that supports the profitability of technical trading rules is provided, among others, by Taylor and Allen(1992) and LeBaron(1999). Both the fundamentalists and the chartists evaluate the fitness of their respective forecasting rules based on the risk adjusted profits and they decide to switch to the most profitable one. Thus, agents are not irrational in our model. They know that they cannot comprehend the full complexity of the underlying model. As a result, the rational response is to try different forecasting rules and to select the one that performs best.

We show that bubbles and crashes occur as a result of the interaction between agents using different forecasting rules. We analyse under which conditions bubbles occur and we study the nature of these bubbles. Next we check if our model reproduces the statistical properties of the exchange rate movements. We argue that our model is capable of explaining the 'anomalies' that have been detected by the empirical evidence which could not be explained by the traditional models. In particular most of the empirical findings document that the exchange rate returns have excess kurtosis and fat tails (see de Vries(2001), Lux T. (1997, 1998), Lux and Marchesi $(1999,2000)$. This evidence is difficult to rationalise in rational expectations efficient market exchange rate models, since there is little evidence of fat tails in the fundamental variables that drive the exchange rate in these models. Other empirical anomalies have been uncovered over the years. One is the "excess volatility" puzzle of the exchange rate, i.e. the volatility of the exchange rate by far exceeds the volatility of the underlying economic variables (Baxter and Stockman (1989) and Flood and Rose (1995)). We show that this puzzle can easily be rationalized in our model. Finally we compute the profits and losses that chartists and fundamentalists make depending on the accuracy of their respective forecasting rules.

\footnotetext{
${ }^{4}$ The fact that agents interpret in a different way the same information has been confirmed empirically by Kandel and Pearson(1995).
} 


\section{The model}

In this section we develop a simple model of the exchange rate. The model consists of three building blocks. First, agents select their optimal portfolio using a mean-variance utility framework. Second, they make forecasts about the future exchange rate based on simple but different rules. Third, they evaluate these rules ex-post by comparing their risk-adjusted profitability.

\subsection{The optimal portfolio}

We assume agents of different types i depending on their beliefs about the future exchange rate. Each agent can invest in two assets, a domestic and a foreign one. The agents' utility function can be represented by the following equation:

$$
U\left(W_{t+1}^{i}\right)=E_{t}\left(W_{t+1}^{i}\right)-\frac{1}{2} \mu V^{i}\left(W_{t+1}^{i}\right)
$$

where $W_{t+1}^{i}$ is the wealth of agent of type $\mathrm{i}$ at time $\mathrm{t}+1, E_{t}$.is the expectation operator, $\mu$ is the coefficient of risk aversion and $V^{i}\left(W_{t+1}^{i}\right)$ represents the conditional variance of wealth of agent $i$. The wealth is specified as follows:

$$
W_{t+1}^{i}=\left(1+r^{*}\right) s_{t+1} d_{t}^{i}+1+r\left(W_{t}^{i}-s_{t} d_{t}^{i}\right)
$$

where $r$ and $r^{*}$ are respectively the domestic and the foreign interest rates, $s_{t+1}$ is the exchange rate at time $\mathrm{t}+1, d_{i, t}$ represents the holdings of the foreign assets by agent of type i at time t. Thus, the first term on the right-hand side of 2 represents the value of the foreign portfolio in domestic currency at time $\mathrm{t}+1$ while the second term represents the value of the domestic portfolio at time $\mathrm{t}+1$.

Substituiting equation 2 in 1 and maximising the utility with respect to $d_{i, t}$ allows us to derive the standard optimal holding of foreign assets by agents of type i :

$$
d_{i, t}=\frac{\left(1+r^{*}\right) E_{t}^{i}\left(s_{t+1}\right)-(1+r) s_{t}}{\mu \sigma_{i, t}^{2}}
$$

The optimal holding of the foreign asset depends on the expected excess return corrected for risk. The market demand for foreign assets at time $t$ is the sum of the individual demands, i.e.:

$$
\sum_{i=1}^{N} n_{i, t} d_{i, t}=D_{t}
$$

where $n_{i, t}$ is the number of agents of type i.

Market equilibrium implies that the market demand is equal to the market supply $X_{t}$ which we assume to be exogenous ${ }^{5}$. Thus,

\footnotetext{
${ }^{5}$ The market supply is determined by the net current account and by the sales or purchases of foreign exchange of the central bank. We assume both to be exogenous. In an extension of this paper we intend to endogenise the market supply.
} 


$$
X_{t}=D_{t}
$$

Substituting the optimal holdings into the market demand and then into the market equilibrium equation and solving for the exchange rate $s_{t}$ yields the equilibrium exchange rate:

$$
s_{t}=\left(\frac{1+r^{*}}{1+r}\right) \frac{1}{\sum_{i=1}^{N} \frac{n_{i, t}}{\sigma_{i, t}^{2}}}\left[\sum_{i=1}^{N} w_{i, t} \frac{E_{t}^{i}\left(s_{t+1}\right)}{\sigma_{i, t}^{2}}-\mu \frac{X_{t}}{1+r}\right]
$$

where $w_{i, t}=n_{i, t} \backslash N$,.i.e. the weight (share) of agent $i$. In order to model the expectations formation we assume that there are two types of agents: chartists and fundamentalists. As a result equation 6 specialises to :

$$
s_{t}=\left(\frac{1+r^{*}}{1+r}\right) \frac{1}{\left(\frac{n_{f, t}}{\sigma_{f, t}}+\frac{n_{c, t}}{\sigma_{c, t}}\right)}\left[w_{f, t} \frac{E_{t}^{f}\left(s_{t+1}\right)}{\sigma_{f, t}^{2}}+w_{c, t} \frac{E_{t}^{c}\left(s_{t+1}\right)}{\sigma_{c, t}^{2}}-\mu \frac{X_{t}}{1+r}\right]
$$

Thus the exchange rate is determined by the expectations of fundamentalists, $E_{t}^{f}$, and chartists $E_{t}^{c}$ about the future exchange rate. These forecasts are weighted by their respective variances $\sigma_{f, t}^{2}$ and $\sigma_{c, t}^{2}$. Thus, when for example the chartists' forecasts have a high variance the weight of the chartists in the determination of the market exchange rate is reduced.

\subsection{The forecasting rules}

We now specify how fundamentalists and chartists.form their expectations of the future exchange rate. In a second step we will specify how they take into account the risk as measured by the variances.

The fundamentalists base their forecast on a comparison between the market and the fundamental exchange rate, i.e. they forecast the market rate to return to the fundamental rate in the future. In this sense they use a negative feedback rule that introduces a mean reverting dynamics in the exchange rate. The speed with which the market exchange rate returns to the fundamental is assumed to be determined by the speed of adjustment in the goods market which is assumed to be in the information set of the fundamentalists (together with the fundamental exchange rate itself). Thus, the forecasting rule for the fundamentalists is :

$$
E_{t}^{f}\left(\Delta s_{t+1}\right)=-\psi\left(s_{t}-s_{t}^{*}\right)
$$

where $s_{t}^{*}$ is the fundamental exchange rate at time $t$, which is assumed to follow a random walk and $0<\psi<\infty$.

The chartists forecast the future exchange rate by extrapolating past exchange rate movements. Their forecasting rule can be specified as : 


$$
E_{t}^{c}\left(\Delta s_{t+1}\right)=\beta \sum_{i=0}^{T} \alpha_{i} \Delta s_{t-i}
$$

Thus, the chartists compute a moving average of the past exchange rate changes and they extrapolate this into the future exchange rate change. The degree of extrapolation is given by the parameter $\beta$. Note that in contrast to the fundamentalists, chartists take into account information concerning the fundamental exchange rate indirectly, i.e. through the exchange rate itself. However, they also take into account other bits of information which are reflected in the exchange rate. In particular they take into account the "market sentiments". They buy and sell according to trends that they detect in the market. In this sense the chartist rule can also be seen as reflecting herding behaviour.

Our choice to give a prominent role to chartists' rules of forecasting is based on empirical evidence. The evidence that chartism is used widely to make forecasts is overwhelming (see Cheung and Chinn(1989), Taylor and Allen(1992)). It remains important, however, to check if the model is internally consistent. In particular, the chartists' forecasting rule must be shown to be profitable within the confines of the model. If these rules turn out to be unprofitable, they will not continue to be used. We return to this issue when we let the number of chartists be determined by the profitability of the chartists' forecasting rule.

We now analyse how fundamentalists and chartists evaluate the risk involved in forecasting. The latter is measured by the variance terms in equation 7 , which we define as the weighted average of the squared (one period ahead) forecasting errors made by chartists and fundamentalists, respectively. Thus,

$$
\sigma_{i, t}=\sum_{k=1}^{\infty} \gamma_{k}\left[E_{t-k}^{i}\left(s_{t-k+1}\right)-s_{t-k+1}\right]^{2}
$$

where $\gamma_{k}$ are geometrically declining weights.

\subsection{Fitness of the rules}

The next step in our analysis is to specify how agents evaluate the fitness of these two forecasting rules. The general idea that we will follow is that agents use one of the two rules, compare their (risk adjusted) profitability ex post and then decide whether to keep the rule or switch to the other one. Thus, our model is in the logic of evolutionary dynamics, in which simple decision rules are followed. These rules will continue to be followed if they pass some "fitness" test (profitability test). Another way to interpret this is as follows. When great uncertainty exists about how the complex world functions, agents use a trial and error strategy. They try a particular forecasting rule until they find out that other rules work better. Such a trial and error strategy can be considered to be a rational strategy when agents cannot understand the full complexity of the underlying model. It can even be argued that it is a more rational strategy than the strategy followed by agents in rational expectations models, where 
these agents have the ambition to understand the underlying model in all its complexity.

We start by specifying the dynamics that governs the number of chartists and fundamentalists, namely $n_{c t}$ and $n_{f t}$. In order to do so, we describe how the number of chartists and fundamentalists changes from period t- 1 to period $\mathrm{t}$ :

$$
\begin{aligned}
& n_{c, t}=n_{c, t-1}+n_{f, t-1} p_{t}^{f c}-n_{c, t-1} p_{t}^{c f} \\
& n_{f, t}=n_{f, t-1}+n_{c, t-1} p_{t}^{c f}-n_{f, t-1} p_{t}^{f c}
\end{aligned}
$$

where $n_{c, t}$ and $n_{f, t}$ are the number of chartists and fundamentalists in period $\mathrm{t}^{6} ; p_{t}^{c f}$ represents the fraction of the chartists who decide to become fundamentalists in period $\mathrm{t}$, and $p_{t}^{f c}$ is the fraction of the fundamentalists who decide to become chartists in period $t$.

These fractions are assumed to be a function of the profitability of the forecasting rules and the risk associated with their use. The fractions are specified as follows ${ }^{7}$ :

$$
\begin{aligned}
p_{t}^{f c} & =\frac{\exp \left[\gamma \pi_{c, t-1}^{\prime}\right]}{\exp \left[\gamma \pi_{c, t-1}^{\prime}\right]+\exp \left[\gamma \pi_{f, t-1}^{\prime}\right]} \\
p_{t}^{c f} & =\frac{\exp \left[\gamma \pi_{f, t-1}^{\prime}\right]}{\exp \left[\gamma \pi_{c, t-1}^{\prime}\right]+\exp \left[\gamma \pi_{f, t-1}^{\prime}\right]}
\end{aligned}
$$

where $\pi_{c, t-1}^{\prime}$ and $\pi_{f, t-1}^{\prime}$ are the risk adjusted net profits made by chartists' and fundamentalists' forecasting the exchange rate in period t- 1 , i.e. $\pi_{c, t-1}^{\prime}=$ $\pi_{c, t-1}-\mu \sigma_{c, t-1}^{2}$ and $\pi_{f, t-1}^{\prime}=\pi_{f, t-1}-C-\mu \sigma_{f, t-1}^{2}$. We assume that the fundamentalists make a fixed cost $C$ for the collection and processing of fundamental information, while the collection of information by chartists is assumed to be costless $^{8}$.

Equations 13and 14 can be interpreted as follows. When the risk adjusted profits of the chartists' rule increases relative to the risk adjusted net profits of the fundamentalists rule, then the fraction of the fundamentalists who become chartists in period $t$ increases, and vice versa. The parameter which regulates such switches is $\gamma$.This parameter can be interpreted as the rate with which the

\footnotetext{
${ }^{6}$ It should be noted that our modelling approach shares important features with the multiagent based models in which market partecipants evolve over time. However, in contrast with such models the characteristics of our model are independent of the total number of agents in the market.

${ }^{7}$ This specification of the decision rule is often used in discrete choice models. For an application in the market for differentiated products see Anderson, S., de Palma, A., Thisse, J.-F., 1992. The idea has also been applied in financial markets. See Brock and Hommes (1997) and $\operatorname{Lux}(1998)$.

${ }^{8}$ This asymmetry in the treatment of the cost of information for fundamentalists and chartists is not crucial for our results.
} 
chartists and fundamentalists revise their forecasting rules. With an increasing $\gamma$ agents revise their forecasts very frequently. In the limit when $\gamma$ goes to infinity agents revise the forecasting rules instantaneously. When $\gamma$ is low, chartists and fundamentalists revise their forecasts relatively slowly. When $\gamma$ is equal to zero they do not revise their rules. In the latter case the fraction of chartists and fundamentalists is constant and equal to 0.5. Thus $\gamma$ is a measure of inertia in the decision to switch to the more profitable rule. As will be seen this parameter is of great importance in generating bubbles.

Chartists and fundamentalists make a profit when they correctly forecast the direction of the exchange rate movement. They make a loss if they wrongly predict the direction of its movements. The profit (the loss) they make equals the one-period return of investing $\$ 1$.

\section{Solution of the model}

In this section we investigate the properties of the solution of the model. We first study its deterministic solution. This will allow us to analyse the characteristics of the solution that are not clouded by exogenous noise. We use simulation techniques since the non-linearities do not allow for a simple analytical solution. We select " reasonable" values of the parameters, i.e. those that come close to empirically observed values. As we will show later these are also parameter values for which the model replicates the observed statistical properties of exchange rate movements. We will also subject the analysis to an extensive sensitivity analysis.

We first concentrate on the fixed point solutions of the model. In figure 1 we show the solutions of the exchange rate for different initial conditions. We plot the fixed point solutions (attractors) as a function of the different initial conditions ${ }^{9}$. On the horizontal axis we set out the different initial conditions. These are initial shocks to the deterministic system. The vertical axis shows the solutions corresponding to these different initial conditions. The fundamental exchange rate was normalized at 0 . We find two types of fixed point solutions. First, for small disturbances in the initial conditions the fixed point solutions coincide with the fundamental exchange rate. We will call these solutions the fundamental solutions. Second, for large disturbances in the initial conditions, the fixed point solutions diverge from the fundamental. We will call these attractors, bubble attractors. It will become clear why we label these attractors in this way. The larger is the initial shock (the noise) the farther the fixed points are removed from the fundamental exchange rate. The border between these two types of fixed points is characterised by discontinuities. This has the implication that in the neigborhood of the border a small change in the initial condition (the noise) can have a large effect on the solution.

The different nature of these two types of fixed point attractors can also be seen from an analysis of the chartists' weights that correspond to these different

\footnotetext{
${ }^{9}$ These fixed point solutions of the exchange rate where obtained by running simulations of 100,000 periods. Each time the exchange rate converged to a fixed point.
} 


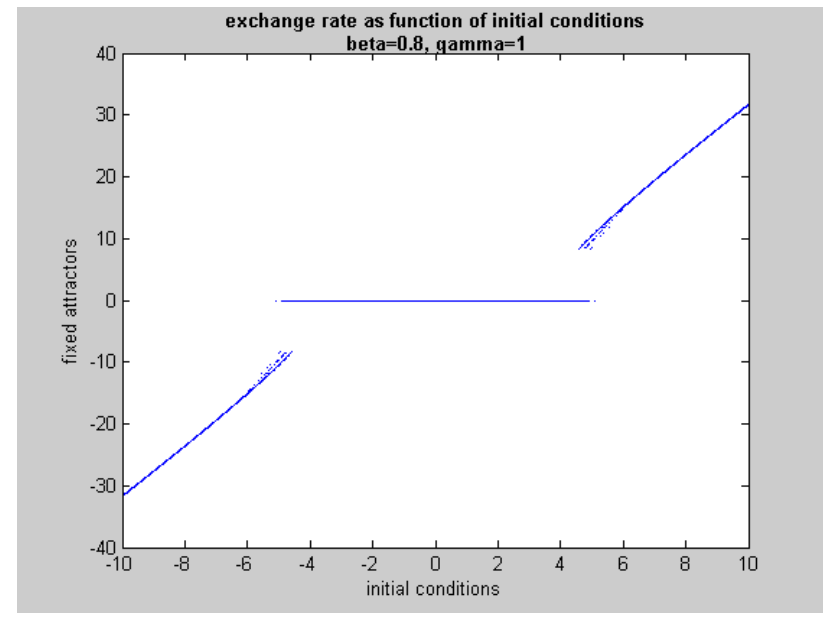

Figure 1:

fixed point attractors. We show these chartists weight as a function of the initial concitions in figure 2.

We find, first, that for small initial disturbances the chartists' weight converges to a number slightly above $50 \%$ of the market. Thus when the exchange rate converges to the fundamental rate, the weight of the chartists and the fundamentalists are approximately equal to $50 \%$. For large initial disturbances, however, the chartists' weight converges to 1 . Thus, when the chartists take over a sufficiently large part of the market, the exchange rate converges to a bubble attractor. The meaning of a bubble attractor can now be understood better. It is an exchange rate equilibrium that is reached when the number of fundamentalists has become sufficiently small (the number of chartists has become sufficiently large) so as to eliminate the mean reversion dynamics. It will be made clearer in the next section why fundamentalists drop out of the market. Here it suffices to understand that such equilibria exist. It is important to see that these bubble attractors are fixed point solutions. Once we reach them, the exchange rate is constant. Such a constant exchange rate occurs then as a result of two situations. One is that the chartists have taken over the whole market. In this case, chartists who extrapolate the past movements, will forecast no change. At the same time, since the fundamentalists have left the market, there is no force acting to bring back the exchange rate to its fundamental value. The other case is when the fundamentalists still have a small market share which exerts some mean reverting pressure. This pressure is, however, offset by the extrapolating pressure exerted by the chartists. Thus two types of equilibria exist: a fundamental equilibrium where chartists and fundamentalists co-exist, and a bubble equilibrium where the chartists have completely or almost completely crowded out the fundamentalists. 


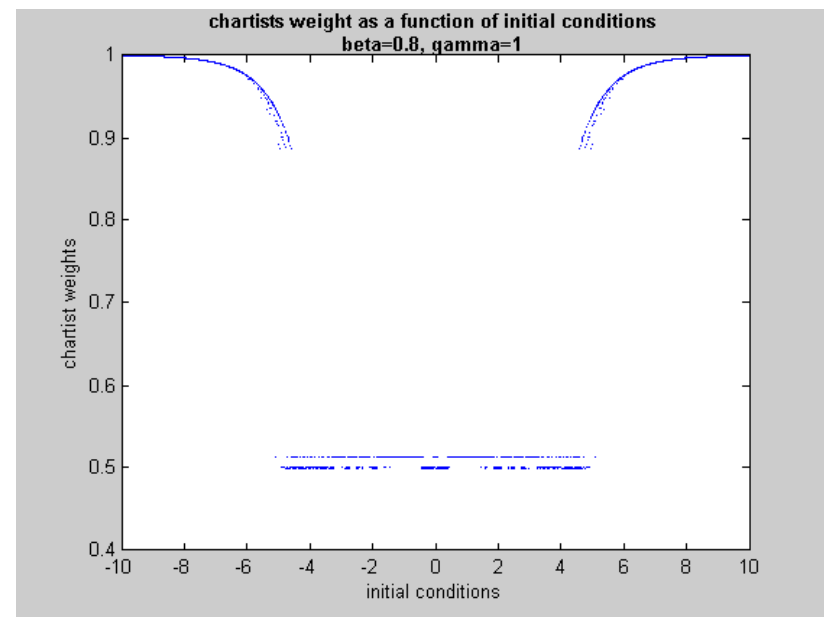

Figure 2:

These two types of equilibria differ in another respect. The fundamental equilibrium can be reached from many different initial conditions. It is locally stable, i.e after small disturbances the system returns to the same (fundamental) attractor. In contrast there is one and only one initial condition that will lead to a particular bubble equilibrium. This implies that a small disturbance leads to a displacement of the bubble solution. Note again that the border between these two types of equilibria is characterized by discontinuities and complexity, i.e. small disturbances can lead to either a fundamental or a bubble equilibrium.

It is useful to compute the attractors for different values of the fundamental exchange rate keeping initial conditions constant. We show such an exercise in figure 3. We now present different fundamental values of the exchange rate on the horizontal axis while keeping the initial condition unchanged. We have set the initial condition for the exchange rate equal to 4 . We obtain the following results. First when the fundamental shock and the initial condition are opposite in sign, the exchange rate converges to its fundamental value. This can be seen by the fact that for negative values of the fundamental shocks, the attractors are on a $45^{\circ}$ line so that the equilibrium exchange rate equals its fundamental value. In the range of fundamental shocks between 0 and 4 we obtain bubble equilibria. This is the range in which the initial shock (noise) has the same sign as the fundamental shock. When the positive fundamental shock becomes large relative to the positive initial shock the system returns to a fundamental equilibrium. Thus, bubble equilibria arise when the fundamental shock and the noise have the same sign, and when the noise is relatively large with respect to the fundamental shock. With sufficiently large fundamental shocks (relative to the noise) the equilibrium exchange rate is forced back to its fundamental value. In appendix 1 we show some additional simulations for smaller and larger initial 


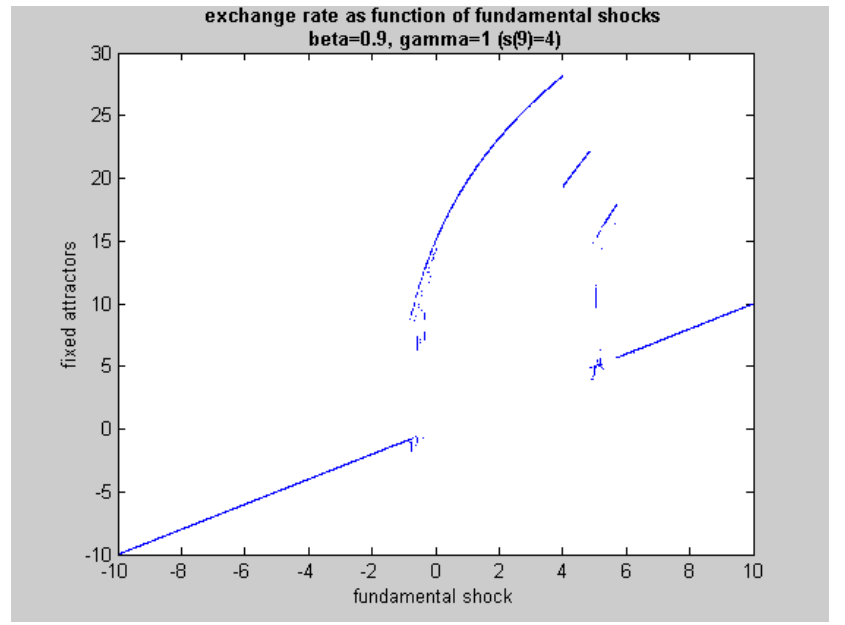

Figure 3:

conditions. These simulations confirm that as the noise increases relative to the fundamental shocks the range of bubble equilibria increases and vice versa.

The previous results allow us to understand not only why bubbles can arise. They also shed light on why bubbles tend to crash. The noise that triggers a bubble is temporary. Fundamental shocks, however, typically have a large permanent component ${ }^{10}$. Thus, in a stochastic environment small fundamental shocks accumulate to large cumulative fundamental changes. These cumulative changes in the fundamental exchange rate at some point become overwhelming leading to a crash. We will return to this result when we present the stochastic simulations of the model.

\section{The anatomy of bubbles and crashes}

In the previous section we identified the existence of two different types of fixed point solutions, i.e. a fundamental solution characterised by the fact that the exchange rate converges to its fundamental value while chartists and fundamentalists "co-habitate", and a bubble solution in which the exchange rate deviates from its fundamental value and in which chartists dominate the market. In this section we show that in combination with stochastic shocks in the fundamental exchange rate these features of the model lead to the emergence of bubbles and crashes.

The way we proceed is to calibrate the model in such a way that it replicates the statistical properties of observed exchange rate movements. We describe this procedure in section 6 . Here we present the results of simulations in the time

\footnotetext{
${ }^{10}$ In the simulations reported here a fundamental shock is permenent.
} 
domain using this calibrated model. We start by presenting a case study of a typical bubble and crash scenario as produced by the stochastic version of the model. In the next section we will analyse more systematically the factors that determine the frequency with which such bubbles and crashes occur. Figure 4 top panel shows the exchange rate and its fundamental value in the time domain; the bottom panel shows the weight of the chartists in the same time domain. These two pictures allow us to analyze a number of common features of a typical endogenously generated bubble and crashes in a stochastic environment.
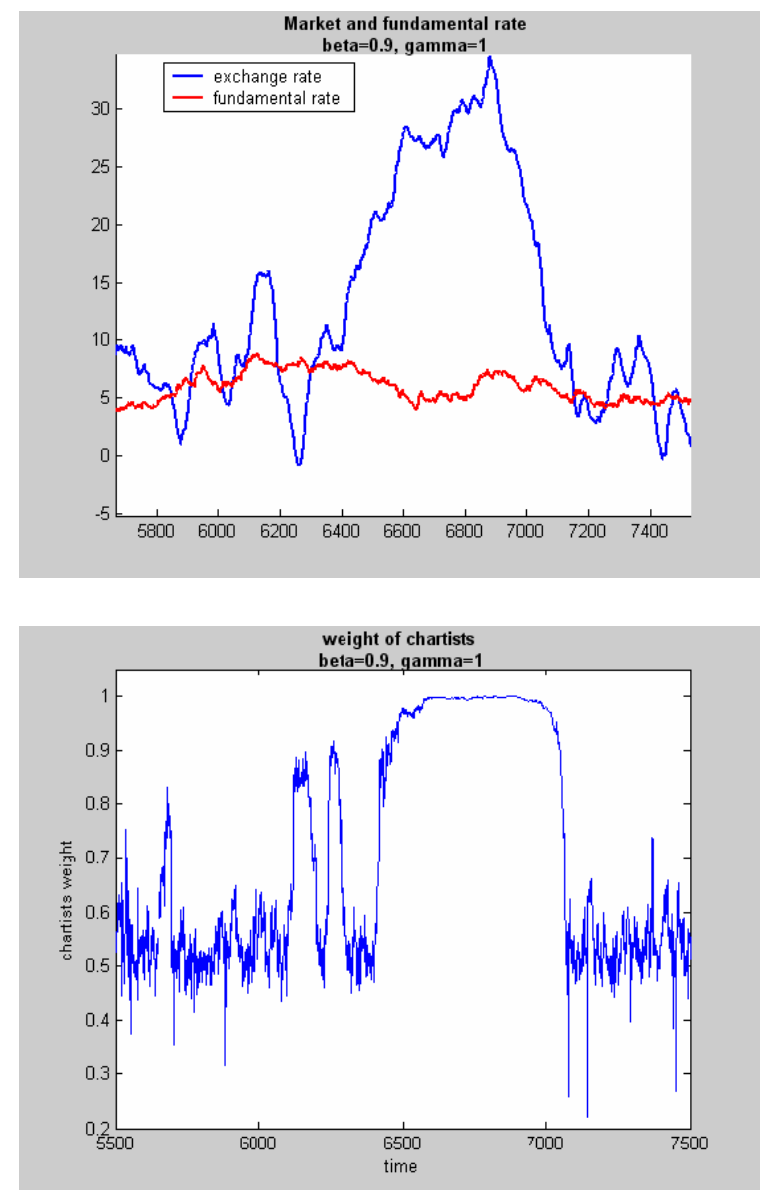

Figure 4:

First, once a bubble emerges, it sets in motion bandwagon effects. As the exchange rate moves steadily in one direction, the use of extrapolative forecasting rules becomes more profitable, thereby attracting more chartists in the market. This is clearly visible from a comparison of the bottom panel with the top panel 
of figure 4. We observe that the upward movement in the exchange rate coincides with an increase in the weight of chartists in the market. We have checked this feature in many bubbles produced by the model. In appendix 2 we show another example of a bubble, and we present the results of a causality test which shows that the exchange rate leads the weight of chartists during a bubble and the subsequent crash. Thus, typically a bubble starts after the exchange rate has moved in one direction, thereby attracting extrapolating chartists which in turn reinforces the exchange rate movement.

Second, a sustained upward (downward) movement of the exchange rate will not develop into a full scale bubble if at some point the market does not get sufficiently dominated by the chartists. As can be seen figure 4 at the height of the bubble the chartists have almost $100 \%$ of the market. Put differently, an essential characteristic of a bubble is that at some point almost nobody is willing to take a contrarian fundamentalist view. The market is then dominated by agents who extrapolate the bubble into the future. This raises the question of why fundamentalists do not take an opposite position thereby preventing the bubble from developing. After all, the larger the deviation of the exchange rate from the fundamental the more the fundamentalists expect to make profit from selling the foreign currency. Yet they do not, and massively leave the marketplace to the chartists. The reason why they do so, is that during the bubble phase the profitability of chartism increases dramatically precisely because so many chartists enter the market thereby pushing the exchange rate up and making chartism more profitable. There is therefore a self-fulfiling dynamics in the profitability of chartism.

The limit of this dynamics is reached when almost everybody has become a chartist. We arrive at our next characteristics of the bubble-crash dynamics. When almost everybody is a chartist the self-reinforcing upward movement in the exchange rate and in profitability slows down, increasing the expected relative profitability of fundamentalists. This is so because while the bubble developed, the expected profits from fundamentalism also increased. However, these were overwhelmed by the self-fulfilling profitabilitty of chartism. When the latter tends to slow down, fundamentalism becomes attractive again. A small movement of the exchange rate can then trigger a fast decline in the share of chartism, back to its normal level of a tranquil market.A crash is set in in motion.

We have described the dynamics of bubbles in qualitative terms, although the underlying model that produces it is quantitative in nature. However, its complexity is such that sometimes a qualitative and fuzzy description comes closer to understanding its nature. We also did this because our qualitative description of the bubble and crashes is reminiscent of the classic description of bubbles and crashes by Kindleberger in his " Manias, Panics, and Crashes. A History of Financial Crises", which despite its qualitative nature has led to a deeper understanding of the nature of bubbles and crashes than has been possible by quantitative models. The remarkable feature of our mathematical 
model is that it produces a story that is very close to Kindleberger's story ${ }^{11}$.

\section{The frequency of bubbles}

In the previous sections we showed that a very simple model is capable of generating bubbles and crashes that have the basic features of bubbles and crashes observed in financial markets. All we need is the existence of agents who maximize the utility of their portfolio, make forecasts based on the use of different forecasting rules and who switch to the more profitable of these rules. An important issue here concerns the frequency with which bubbles occur in our model. We analyse this issue by simulating the stochastic version of the model and by counting the number of periods the exchange rate is involved in a bubble. We define a bubble here to be a deviation of the exchange rate from its fundamental value by more than three times the standard deviation of the fundamental variable for a significant interval of time. We have set this interval equal to 20 periods.We show the result of such an exercise in figure 5 for different values of the extrapolation parameter $\beta$. It shows the percentage of time the exchange rate is involved in a bubble dynamics. We observe that when $\beta$ is smaller than 1 the frequency of the occurrence of bubbles is reasonable. For values of $\beta$ larger than 1 this frequency increases exponentially. Thus the extrapolation by chartists is an important parameter affecting the frequency with which bubbles occur. The results obtained in figure 5 are determined by the existence of bubble

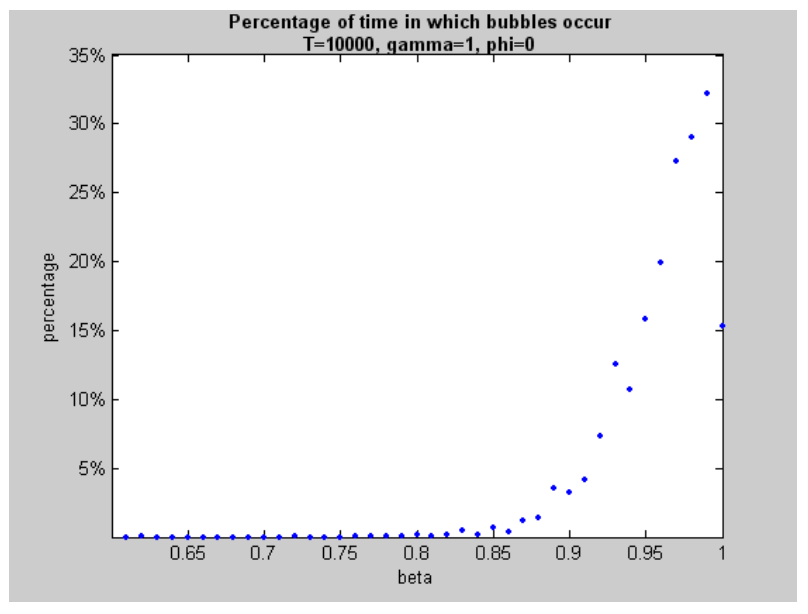

Figure 5:

equilibria in the deterministic version of the model. Therefore, it is useful to

\footnotetext{
${ }^{11}$ A bubble is:" ... a sharp rise in price of an asset or a range of assets in a continous process, with the initial rise generating expectations of further rises and attracting new buyers-generally speculators, interested in profits from trading in the asset rather than its use as earning capacity". Kindleberger(1987).
} 
connect figure 5 with a figure that plots the exchange rate solutions obtained in the deterministic version of the model. We show this in figure 6 where we set out the equilibrium exchange rate on the vertical axis as a function of $\beta$ (horizontal axis). We see that for values of $\beta<0.85$, the exchange rate converges to its fundamental value (normalized to 0 ). When $\beta>0.85$ we obtain bubble equilibria that increasingly deviate from the fundamental value. Note that when $0.88<\beta<0.9$ we have a complex structure. The equilibrium jumps back and forth between the fundamental and a bubble. Thus, in a way figure 6 predicts what should happen in a stochastic environment. When $\beta<0.85$ the equilibrium exchange rate converges to its fundamenal value. Around this fundamental value a basin of attraction exists which pulls the exchange rate. Only when the noise is sufficiently high will the exchange rate be attracted to a bubble equilibrium (see figure 1 where we showed that with $\beta=0.8$ a sufficiently high initial shock will pull the exchange rate towards a bubble equilibium). Thus, when $\beta<0.85$ bubbles will be relatively infrequent events. When $\beta$ increases above 0.85 , however, bubble equilibria appear, increasing the probability of bubbles in a stochastic environment. Note however that even when $\beta$ is larger enough (e.g. $0.9)$ to produce only bubble equilibria in the deterministic version of the model, the probability of a bubble is not 1 in the stochastic version. The reason is that the noise can lead the exchange rate within the basin of attraction around the fundamental or, more importantly, that the shocks in the fundamentals displace the basin of attraction leading to a crash in the bubble.

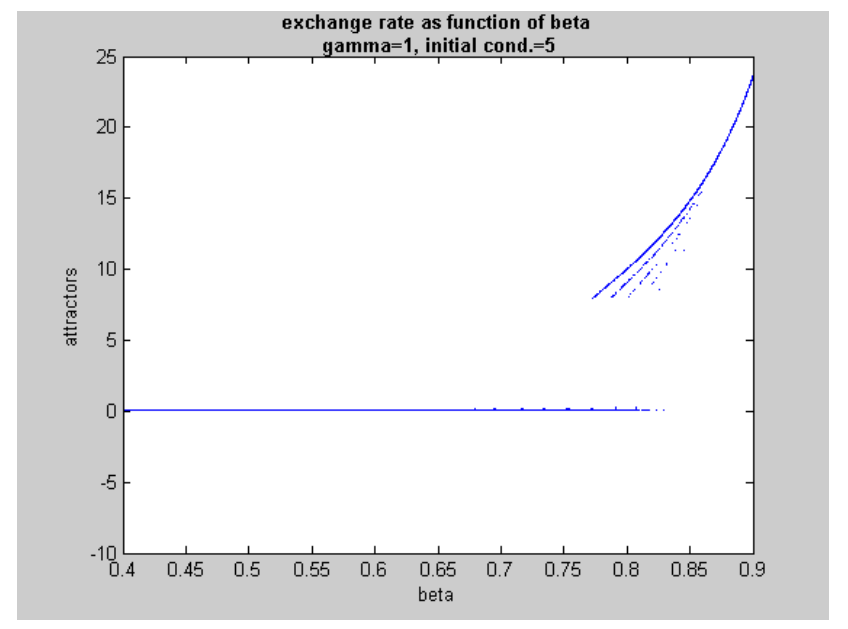

Figure 6:

From the analysis of the different types of equilibria made in section 3, we predicted that bubbles are more likely to occur when the size of the noise is large relative to the size of the shocks in the fundamental. We now test this prediction in the stochastic environment. We proceed as follows. We first 
simulate the model assuming that the variance of the noise is $50 \%$ higher than the variance of the shocks in the fundamentals. We then perform a simulation with the reverse assumption, i.e. the variance of the shocks in the fundamentals is $50 \%$ higher than the variance of the noise. We show the results in figure 7 . We find that the percentage of time in which bubbles occur is about twice as high when the variance of the noise is high relative to the variance of the shocks in the fundamental (left panel). This result is interesting for the following reason. It is often said that if the authorities reduce the variability of the fundamental variables (inflation, money growth, etc.) the exchange rate will also become less volatile. Our results indicate that this may not be so. If the noise is high relative to volatility of fundamentals, bubbles may even become more frequent ${ }^{12}$. The frequency of the occurrence of bubbles also depends on the parameter $\gamma$

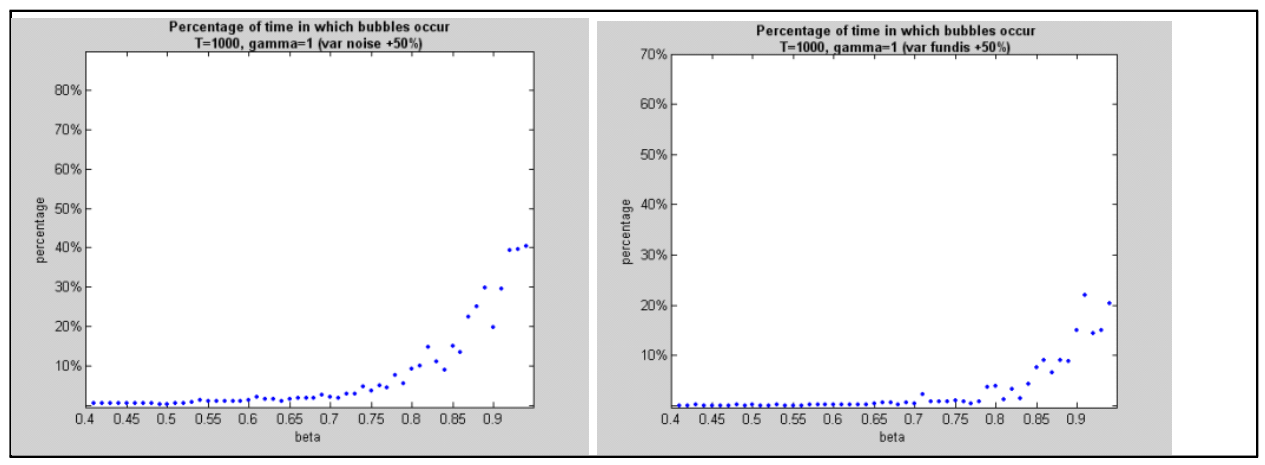

Figure 7:

which measures the rate with which chartists and fundamentalists revise their forecasting rules. We have called this parameter rate of revision. In a way, $\gamma$ also measures the speed with which agents learn about the profitability of the other rule and revise their forecasts. The lower is this parameter the less frequently agents will revise their forecasting rules. In the limit when $\gamma=0$ the agents never revise their forecasts which could be interpreted as a world which agents perceive to be stationary.

In order to illustrate the importance of this parameter, we first show the results of the deterministic simulations in figures 8 . We observe that for values of $\gamma$ lower than (approximately) 1.2 the exchange rate converges to its fundamental value. For higher values we obtain bubble equilibria ${ }^{13}$. Note also a zone of complexity where the location of the bubble equilibria is very sensitive to small changes in the parameter $\gamma$. In figure 9 we show the results of the stochastic simulation under the same parameter configuration. We observe that

\footnotetext{
${ }^{12}$ It is also worth pointing out that despite the dramatic decline of the variability of important fundamental variables like inflation during the last twenty years, there is no evidence that the exchange rates of the major currencies have become less volatile.

${ }^{13}$ In appendix 3 we show a similar figure where we have set $\beta=0.9$. In that case the critical value of $\gamma$ which produces bubble equilibria is lowered.
} 
for low values of $\gamma$ the occurence of bubbles is very infrequent. As $\gamma$ increases the frequency of bubbles increases significantly.

The previous results allow us to shed some additional light on the nature of bubbles and crashes. As we have seen before, bubbles arise because agents are attracted by the profitability of the extrapolating (chartist) rule, and this attraction in turn makes this forecasting rule more profitable, leading to a selffulfilling increase in profitability. For this dynamics to work, agents' decision to switch must be sufficiently sensitive to the relative profitabilities of the rules. If it is not, no bubble equilibria can arise, as is the case when $\gamma$ does not exceed 1. The larger is $\gamma$ the more likely it is that these self-fulfilling bubble equilibria arise. The interesting aspect of this result is that in a world where agents quickly react to changing profit opportunities, bubbles become more likely than in a world where agents do not react quickly to these new profit opportunities. One way to interpret this result could be the following. When $\gamma$ is low, agents do not quickly adjust their forecasting rules to changing relative profitabilities. This must be a world that they perceive to be stationary in which there is no need to switch in and out of different forecasting rules. In such a world, bubbles are unlikely to occur. Conversely, in a world where agents react to every whimp in relative profitabilities bubbles will be a frequent occurrence.

The policy implication of this result is that by increasing the inertia in the system so that agents react less quickly to changes in relative profitabilities of forecasting rules, the authorities could reduce the probability of the occurrence of bubbles. How this can be done and whether some form of taxation of exchange transactions can do this, is a question we want to analyse in future research.

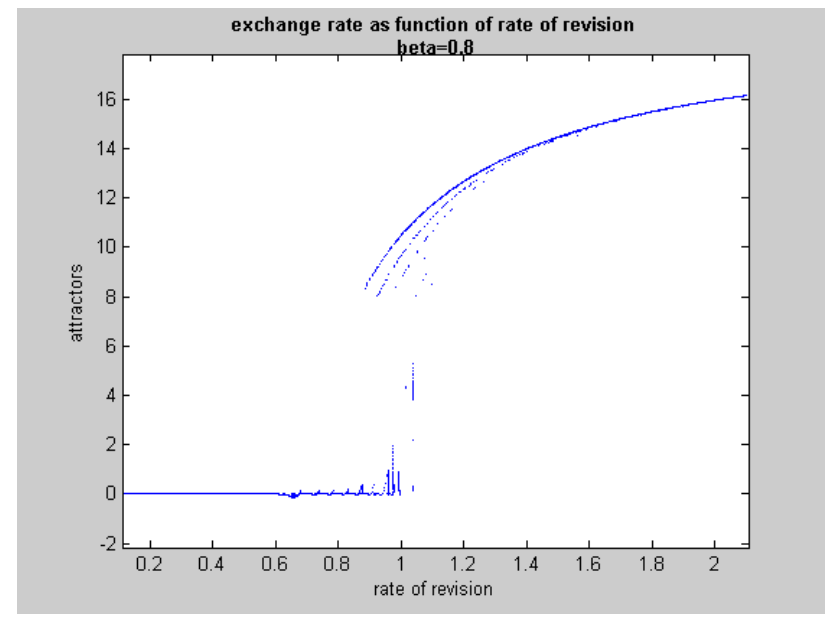

Figure 8: 


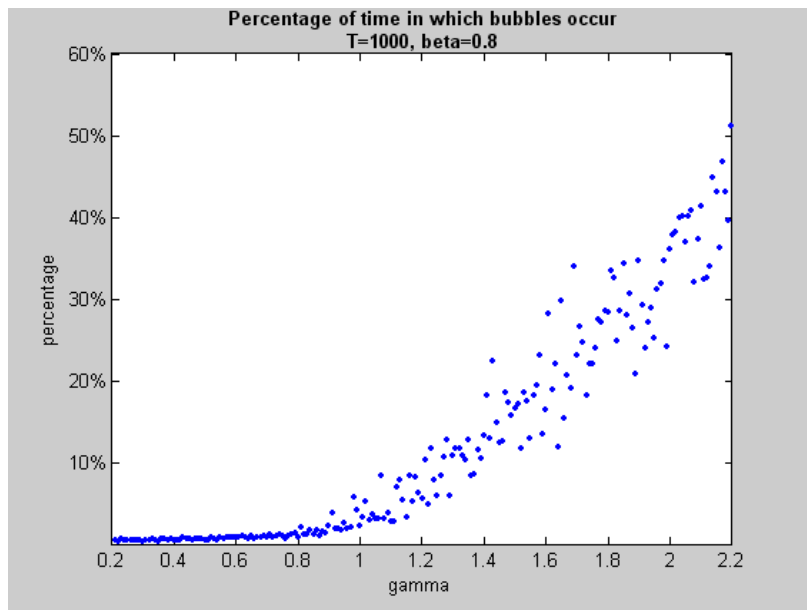

Figure 9:

\section{Fundamentalism and risk}

In the previous sections we showed how bubbles and crashes occur in a world where agents use different forecasting rules. The essence of the dynamics is that at some point extrapolative forecasting (chartism) becomes more profitable than mean-reversion forecasting (fundamentalism). This attracts more chartists enhancing the profitability of extrapolative forecasting. At the same time fundamentalism becomes loss making driving agents away from this kind of forecasting.

An implicit assumption in the model is that as the exchange rate moves away from its fundamental during the bubble, fundamentalists' perception of the risk in taking a "contrarian" i.e. fundamentalist position remains unaffected by the increasing "misalignment" of the exchange rate. This assumption is crucial because it explains why in the bubble phase fundamentalists massively decide to become chartists.

In this section we assume that fundamentalists' perception of the risk in taking a fundamentalist position during the bubble changes and increases with the misalignment. Put differently, we will now assume that as the misalingment increases during the bubble, fundamentalists become increasingly confident that their contrarian forecast is correct. Thus, while their fundamentalist forecast is loss-making during the bubble, the fundamentalists find it increasingly less risky to make such a forecast as we move along the bubble path.

We use the same model as in the previous sections except that we amend the equations describing the switches from fundamentalist to chartist forecasting rules. In order to facilitate the reading we reproduce this equation here: 


$$
p_{t}^{f c}=\frac{\exp \left[\gamma \pi_{c, t-1}^{\prime}\right]}{\exp \left[\gamma \pi_{c, t-1}^{\prime}\right]+\exp \left[\gamma \pi_{f, t-1}^{\prime}\right]}
$$

where $\pi_{c, t-1}^{\prime}$ and $\pi_{f, t-1}^{\prime}$ are the risk adjusted net profits made by chartists' and fundamentalists' forecasting the exchange rate in period t-1, i.e. $\pi_{c, t-1}^{\prime}=$ $\pi_{c, t-1}-\mu \sigma_{c, t-1}^{2}$ and $\pi_{f, t-1}^{\prime}=\pi_{f, t-1}-C-\mu \sigma_{f, t-1}^{2}$.

We now redefine the risk component to take into account that the risk perception of the fundamentalists declines as the misalignment increases. We do this by assuming that the coefficient of risk aversion of fundamentalists can be specified as follows

$$
\mu_{t}^{\prime}=\frac{\mu}{1+\phi\left|s_{t-1}-s_{t-1}^{*}\right|}
$$

where $\phi \geq 0$ is a parameter measuring the sensitivity of the fundamentalists' risk aversion to the degree of misalignment $\left(\left|s_{t-1}-s_{t-1}^{*}\right|\right)$ When $\phi=0$ fundamentalists are not sensitive to the misalignment. With an increasing $\phi$, the fundamentalists' risk aversion declines, making them more willing to take a contrarian position during a bubble.

We redefine the risk adjusted profits of the fundamentalists as follows

$$
\pi_{f, t-1}^{\prime}=\pi_{f, t-1}-C-\mu_{t}^{\prime} \sigma_{f, t-1}^{2}
$$

We now proceed in the same way as before. We first solve the deterministic part of the model We then add the stochastics to the model. We will analyze in particular how sensitive the results are to the coefficient $\phi$, which measures how sensitive is the fundamentalists' risk aversion to the degree of misalignment.

We start by presenting the solution of the exchange rate for different values of $\phi$. We have selected an initial value that in the absence of such sensitivity $(\phi=0)$ produces a bubble equilibrium ${ }^{14}$. The results are shown in figure 10. We observe that when $\phi=0$, a bubble equilibrium exists. However, a relatively small positive value of $\phi$ (in this case $\phi=0.01$ ) is sufficient to eliminate the bubble equilibrium. The exact value of $\phi$ that achieves this depends on the other parameters of the model and on the initial conditions. For example, with high values of $\gamma$ (the parameter which measures the sensitivity of agents to the profitability of the forecasting rules), we need a higher $\phi$ to eliminate bubble equilibria. We show an example in figure 11. In this figure we set the fixed point solutions as a function of the shocks in the fundamental. We have set $\phi=0.5$ and we assume a high sensitivity to profits $(\gamma=10)$ We find that in this case certain shocks can still lead to a bubble equilibrium. For a sufficiently high value of $\phi$ however these bubble equilibria disappear. Thus, for example, when $\phi=0.9$ the bubble equilibria disappear for all shocks. See figure 12. The next step in the analysis is to add the stochastics to the model. As will be remembered, this stochastics comes from the fact that the fundamental exchange rate is driven by

\footnotetext{
${ }^{14}$ It will be remembered that the occurrence of a bubble equilibrium depends on the initial conditions. See section ZZZ
} 


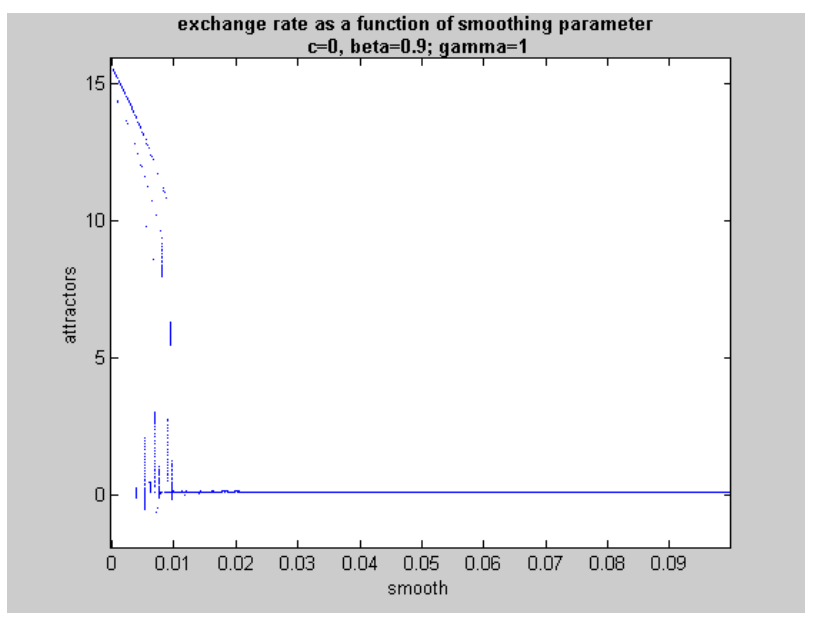

Figure 10:

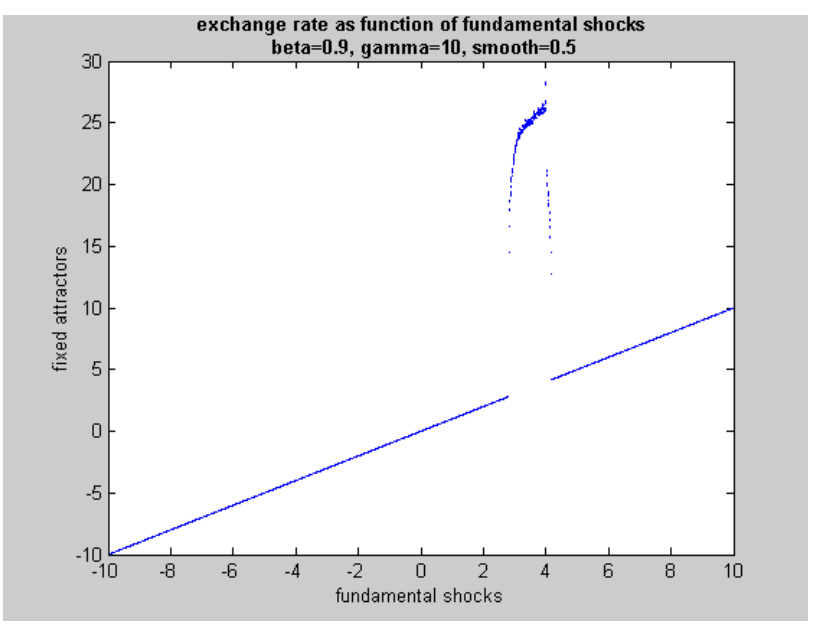

Figure 11: 


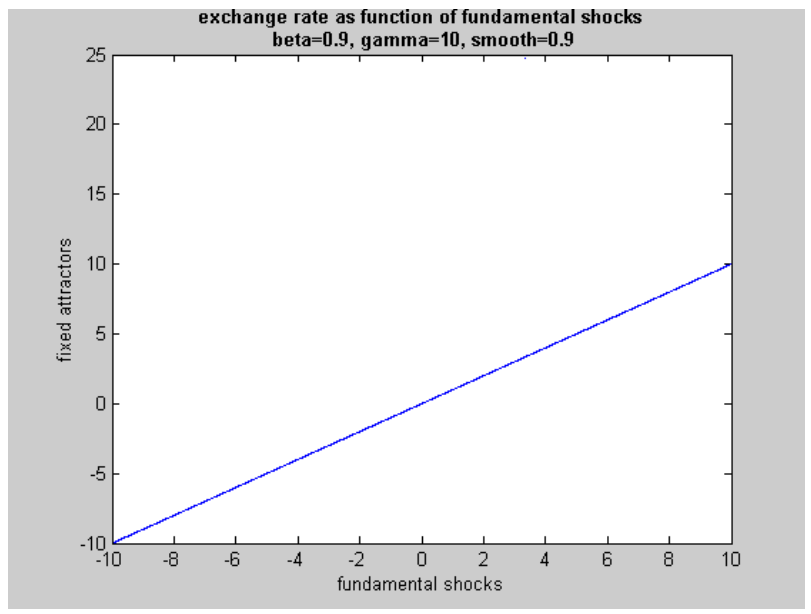

Figure 12:

a random walk process and that the forecasts are influenced by noise. Adding stochastics to the model makes it possible for the attractors to be displaced and to jump from fundamental to bubble equilibria, as described in the previous sections.

We computed the frequency with which bubbles occur in a stochastic environment for different values of the sensitivity of the fundamentalists' risk aversion to misalignment $(\phi)$. We show the results in figure 13. Each simulation is run during 1000 periods $(T=1000)$. We find that when $\phi$ is close to zero the frequency with which bubbles occur is relatively high, certainly much higher than observed in reality. Small increased in $\phi$, however, lead to a significant decline in the frequency of bubbles. For values of $\phi>0.5$ this frequency tends to stabilize around $0.5 \%$.

One can conclude that, not surprisingly, the occurrence of bubbles depends in a significant way on how the fundamentalists perceive the risk of taking a contrarian position when a bubble develops. When the fundamentalists' risk aversion is independent of the degree of misalignment bubbles will occur frequently. When, however, fundamentalists becomes less risk avert as the bubble develops, these bubbles will be less frequent.

\section{Empirical relevance of the model}

In this section we analyse how well our model mimics the empirical anomalies and puzzles that have been uncovered by the flourishing empirical literature. We calibrate the model such that it replicates the observed statistical properties of exchange rate movements. In order to do so we selected a parameter configuration that mimics these properties most closely. We discuss these different 


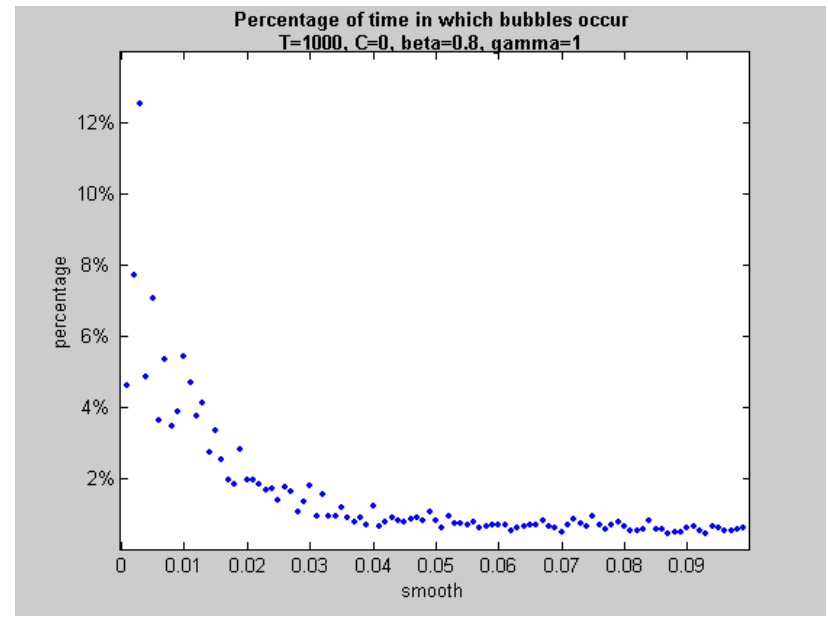

Figure 13:

statistical properties in the following sections.

\subsection{Fat tails and excess kurtosis}

It is well known that the exchange rate changes do not follow a normal distribution. Instead it has been observed that the distribution of exchange rate changes has more density around the mean than the normal and exhibits fatter tails than the normal (see de Vries(2001)). This phenomenon was first discovered by Mandelbrot (1963), in commodity markets. Since then, fat tails and excess kurtosis have been discovered in many other asset markets including the exchange market. In particular, in the latter the returns have a kurtosis typically exceeding $3^{15}$ and a measure of fat tails (Hill index) ranging between 2 and 5 (see Koedijk, Stork and de Vries (1992), Huisman, et al.(2002)). It implies that most of the time the exchange rate movements are relatively small but that occasionally periods of turbulence occur with relatively large exchange rate changes.

In table 1 we show the kurtosis and the Hill.index of the USD-DEM and the JPY-DEM exchange rate returns for the period 1975-1998 . We computed the Hill index for different cut-off points of the tails $(2.5 \%, 5 \%, 10 \%)$ and for 4 different subsamples of the original series. We find that these exchange rates exhibited excess kurtosis and fat tails during the sample period.

Another empirical finding that has bee observed is that the kurtosis is reduced under time aggregation ( see Lux(1998), Calvet and Fisher(2002)). We checked this finding for the same exchange rates. In table 2 we show the results for USD-DEM and JPY-DEM exchange rates, and we confirm that the kurtosis

${ }^{15}$ The normal distibution has a kurtosis index equal to 3 . 
Table 1: Kurtosis and Hill index USD-DEM and JPY-DEM 1975-98

\begin{tabular}{|l|c|c|c|c|}
\hline \multirow{2}{*}{ Exchange rate } & \multirow{2}{*}{ kurtosis } & \multicolumn{3}{|c|}{ median Hill index } \\
\cline { 3 - 5 } & & $\mathbf{2 . 5 \%}$ tail & $\mathbf{5 \%}$ tail & $\mathbf{1 0 \%}$ tail \\
\hline USD-DEM & 12.1 & 4.0 & 3.6 & 3.1 \\
\hline JPY-DEM & 19.6 & 3.7 & 3.6 & 2.9 \\
\hline
\end{tabular}

Table 2: Kurtosis and time aggregation USD-DEM and JPY-DEM 1975-98

\begin{tabular}{|l|c|c|c|}
\hline Parameter values & $\begin{array}{l}5 \text { period } \\
\text { returns }\end{array}$ & $\begin{array}{l}10 \text { period } \\
\text { returns }\end{array}$ & $\begin{array}{l}50 \text { period } \\
\text { returns }\end{array}$ \\
\hline USD-DEM & 7.4 & 5.3 & 3.4 \\
\hline JPY-DEM & 14.9 & 5.7 & 2.7 \\
\hline
\end{tabular}

declines under time aggregation.

The next step in the analysis was to check whether these empirical features are also shared by the simulated exchange rate changes in our model.

The model was simulated using normally distributed random disturbances ( with mean $=0$ and standard deviation $=1$ ). We computed the kurtosis and the Hill index of the simulated exchange rate returns. We computed the Hill index for 4 different samples of 2000 observations. In addition, as before, we considered three different cut-off points of the tails $(2.5 \%, 5 \%, 10 \%)$. We show the results of the kurtosis and of the Hill index in table 3 . We find that for a broad range of parameter values the kurtosis exceeds 3 and the Hill index indicates the presence of fat tails.

In figure 14 we show the probability density of the USD-DEM exchange rate and of our simulated exchange rates, up-left and down-left panel respectively. On the right panel we plot the probability density of normally distributed returns. We observe that the empirical distribution differs from the normal distribution and that it strikingly resembles the distribution of our simulated exchange rate returns. In appendix 3 we present the results for the JPY-DEM exchange rate returns.

Finally we check if the kurtosis of our simulated exchange rate returns declines under time aggregation. In order to do so, we chose different time aggregation periods and we computed the kurtosis of the time-aggregated exchange rate returns. We found that the kurtosis declines under time aggregation. In table 4 we show the results for some sets of parameter values ${ }^{16}$.

The previous results suggest that the speculative dynamics of the model transforms normally distributed noise in the exchange rate into exchange rate movements with tails that are significantly fatter than the normal distribution and with more density around the mean. Thus, our model mimics an important empirical regularity, i.e. that exchange rate movements are characterised by tranquil periods (occurring most of the time) and turbulent periods (occurring

\footnotetext{
${ }^{16}$ Another empirical regularity of the distribution of exchange returns is its symmetry. We computed the skewness, and we could not reject that the distribution is symmetric.
} 

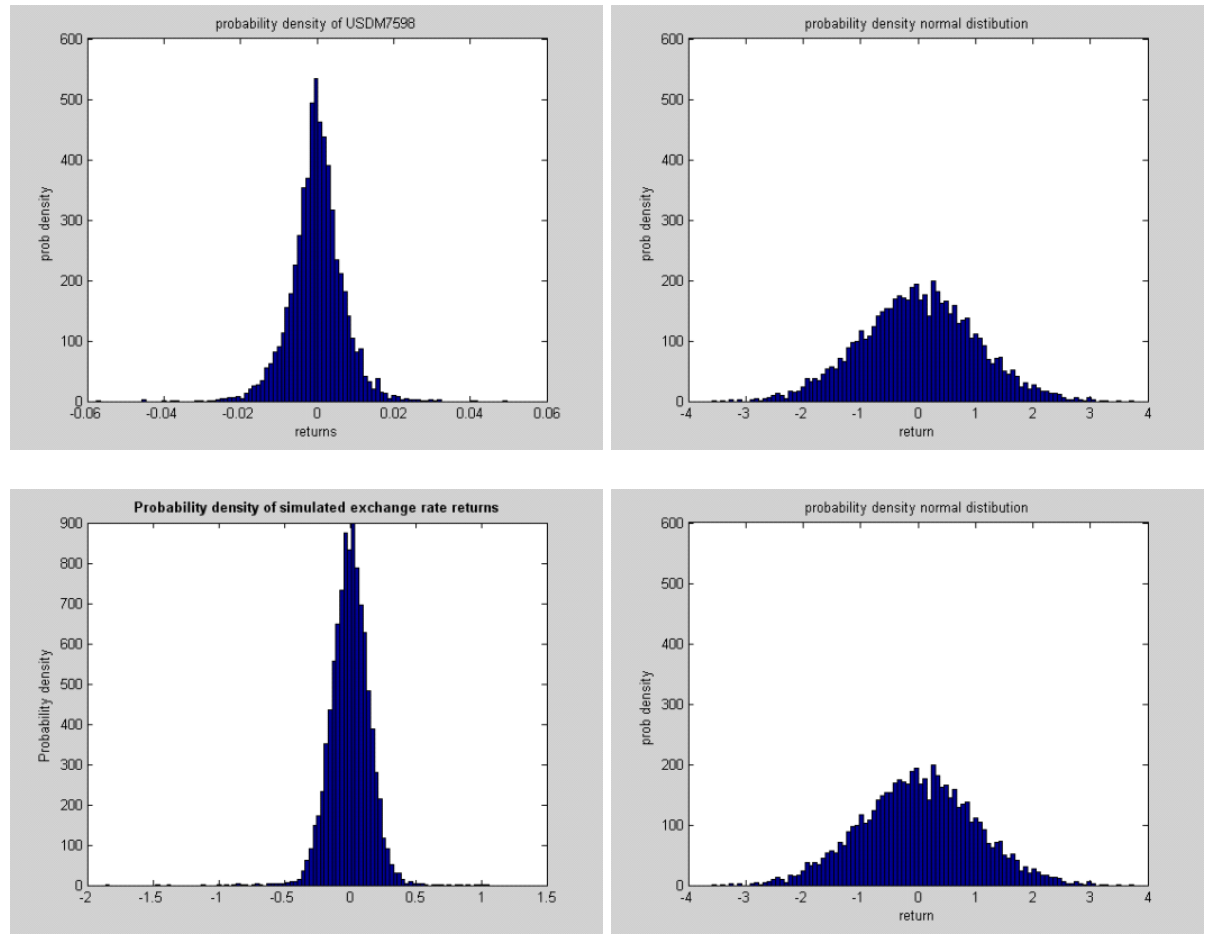

Figure 14:

infrequently).This phenomenon has been also called intermittency phenomenon (see $\operatorname{Lux}(1998))$.

\subsection{The " excess volatility" puzzle}

In this section we analyse another important empirical regularity, which has been called the "excess volatility" puzzle, i.e. the volatility of the exchange rate by far exceeds the volatility of the underlying economic variables. Baxter and Stockman (1989) and Flood and Rose (1995) found that while the movements from fixed to flexible exchange rates led to a dramatic increase in the volatility of the exchange rate no such increase could be detected in the volatility of the underlying economic variables. This contradicted the 'news' models that predicted that the volatility of the exchange rate can only increase when the variability of the underlying fundamental variables increases ( see Obstfeld and Rogoff (1996) for a recent formulation of this model $)^{17}$.

\footnotetext{
${ }^{17}$ In addition, Goodhart (1989) and Goodhart and Figlioli (1991) found that most of the changes in the exchange rates occur when there is no observable news in the fundamental economic variables. This finding contradicted the theoretical models (based on the efficient market hypothesis), which imply that the exchange rate can only move when there is news in
} 
Table 3: Kurtosis and Hill index

\begin{tabular}{|l|c|c|c|c|}
\hline \multirow{2}{*}{ Parameter values } & \multirow{2}{*}{ kurtosis } & \multicolumn{3}{|c|}{ median Hill index } \\
\cline { 3 - 5 } & & $\mathbf{2 . 5 \%}$ tail & $\mathbf{5 \%}$ tail & $\mathbf{1 0 \%}$ tail \\
\hline$\beta=0.9, \gamma=0.001$ & 6.9 & 6.1 & 5.4 & 4.4 \\
\cline { 2 - 5 }$\beta=0.9, \gamma=0.5$ & 11.0 & 7.4 & 5.7 & 4.3 \\
\cline { 2 - 5 }$\beta=0.9, \gamma=1$ & 48.1 & 7.1 & 5.5 & 4.3 \\
$\beta$ & 25.0 & 7.1 & 5.9 & 4.2 \\
\hline$\beta=0.9, \gamma=5$ & 6.9 & 6.6 & 5.2 & 4.4 \\
\hline$\beta=0.8, \gamma=0.001$ & 3.8 & 5.9 & 5.7 & 4.3 \\
\hline$\beta=0.8, \gamma=0.5$ & 9.3 & 7.3 & 5.7 & 4.6 \\
\hline$\beta=0.8, \gamma=5$ & 21.4 & 7.4 & 5.9 & 4.6 \\
\hline
\end{tabular}

Table 4: Kurtosis and time aggregation

\begin{tabular}{|l|c|c|c|c|}
\hline Parameter values & $\begin{array}{l}5 \text { period } \\
\text { returns }\end{array}$ & $\begin{array}{l}10 \text { period } \\
\text { returns }\end{array}$ & $\begin{array}{l}25 \text { period } \\
\text { returns }\end{array}$ & $\begin{array}{l}50 \text { period } \\
\text { returns }\end{array}$ \\
\hline$\beta=0.9, \gamma=0.001$ & 177.7 & 30.9 & 2.9 & 3.2 \\
\hline$\beta=0.9, \gamma=0.5$ & 39.2 & 17.0 & 3.7 & 2.7 \\
$\beta=0.9, \gamma=1$ & 43.3 & 33.4 & 6.7 & 2.9 \\
$\beta=0.9, \gamma=5$ & 46.1 & 40.4 & 9.6 & 2.9 \\
\hline$\beta=0.8, \gamma=0.001$ & 185.7 & 14.3 & 8.5 & 2.5 \\
\hline$\beta=0.8, \gamma=0.5$ & 175.6 & 4.5 & 9.39 & 12.2 \\
\hline$\beta=0.8, \gamma=1$ & 74.1 & 16.2 & 3.0 & 2.2 \\
\hline$\beta=0.8, \gamma=5$ & 90.5 & 30.4 & 3.3 & 2.9 \\
\hline
\end{tabular}


In order to deal with this puzzle we compute the noise to signal ratio in the simulated exchange rate. We derive this noise to signal ratio as follows:

$$
\operatorname{var}(s)=\operatorname{var}(f)+\operatorname{var}(n)
$$

where $\operatorname{var}(\mathrm{s})$ is the variance of the simulated exchange rate, $\operatorname{var}(\mathrm{f})$ is the variance of the fundamental and $\operatorname{var}(\mathrm{n})$ is the residual variance (noise) produced by the non-linear speculative dynamics which is uncorrelated with $\operatorname{var}(\mathrm{f})$. Rewriting (17) we obtain

$$
\frac{\operatorname{var}(n)}{\operatorname{var}(f)}=\frac{\operatorname{var}(s)}{\operatorname{var}(f)}-1
$$

The ratio $\operatorname{var}(n) / \operatorname{var}(f)$ can be interpreted as the noise to signal ratio. It gives a measure of how large the noise produced by the speculative dynamics is with respect to the exogenous volatility of the fundamental exchange rate. We simulate this noise to signal ratio for different values of the extrapolation parameter beta (see figure 15). In addition, since this ratio is sensitive to the time interval over which it is computed we checked how it changes depending on the length of the time interval. In particular, we expect that the noise-to-signal ratio is larger when it is computed on a short than on a long time horizon. We show the results in figure 16 which assumes the same parameter configuration as ??.

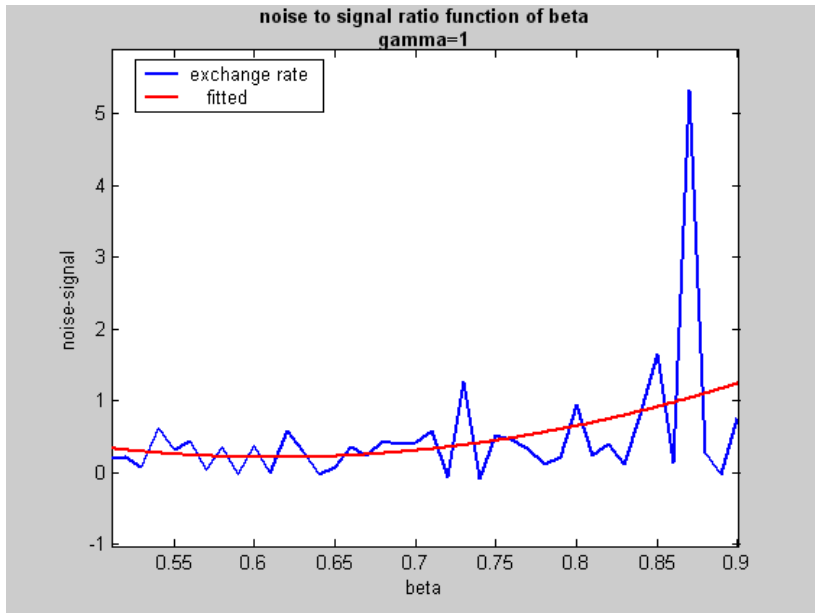

Figure 15:

First, we find that with increasing $\beta$ the noise to signal ratio increases. This implies that when the chartists increase the degree with which they extrapolate the past exchange rate movements, the noise in the exchange rate, which the fundamentals. 


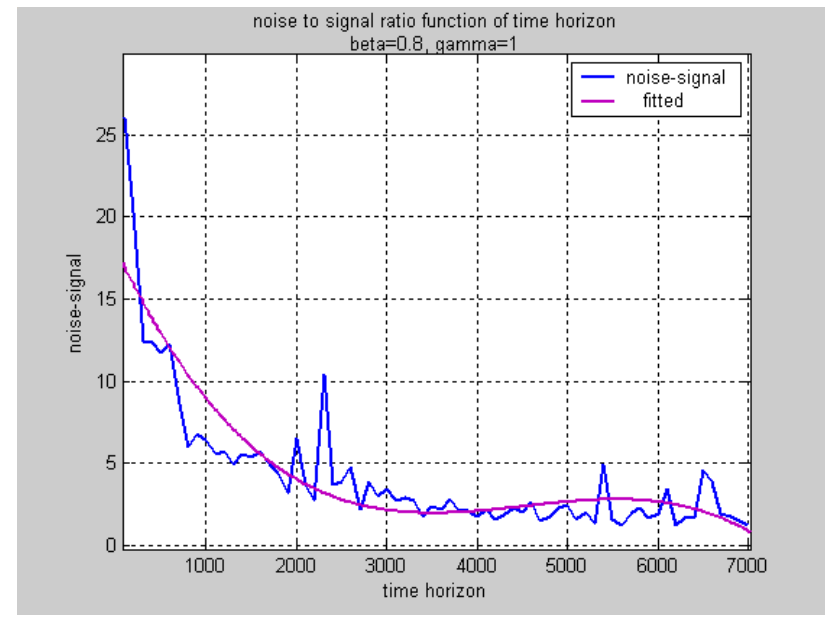

Figure 16:

is unrelated to fundamentals, increases. Thus, the signal about the fundamentals that we can extract from the exchange rate becomes more clouded when the chartists extrapolate more. Second, we find that when the time horizon increases the noise-to-signal ratio declines. This is so because over long time horizons most of the volatility of the exchange rate is due to the fundamentals' volatility and very little to the endogenous noise. In contrast, over short time horizons the endogenous volatility is predominant and the signal that comes from the fundamentals is weak. This is consistent with the empirical findings following Meese and Rogoff(1983) celebrated studies. This literature tells us that when the forecasting horizon increases the performance of forecasting based on fundamentals tends to improve relative to random walk forecasting (see Mark(1995), Faust, et al. (2002)). .

\section{Accuracy and Profitability of Forecasting Rules}

In the previous sections we discussed the statistical properties of our simulated exchange rates. The parameter $\gamma$,i.e. the rate of revision of the forecasts made by the agents, turned to be of crucial importance. We now analyse in more details how the choice of $\gamma$ affects the precision with which agents make forecasts . In order to do so, we compute two measures of accuracy of the forecasting rules. The first measure is the moving average of the forecasting errors, i.e.

$$
A_{i, t}=\sum_{k=1}^{\infty} \gamma_{k}\left[E_{t-k}^{i}\left(s_{t-k+1}\right)-s_{t-k+1}\right]^{2}
$$

It should be noted that this accuracy measure is identical to the variance in the forecasting rules ( see equation 10). 
Table 5: Accuracy of forecasting rules

\begin{tabular}{|c|c|c|c|c|}
\hline & \multicolumn{2}{|c|}{ Accuracy } & \multicolumn{2}{c|}{ Extreme Accuracy } \\
\hline$\gamma$ & fundamentalists & chartists & fundamentalists & chartists \\
\hline 0.01 & 0.11 & 0.09 & 0 & 0 \\
\hline 0.1 & 0.11 & 0.09 & 0 & 0 \\
\hline 1 & 2.21 & 0.08 & 0.95 & 0 \\
\hline 5 & 14.07 & 0.08 & 2.88 & 0 \\
\hline 10 & 15.0 & 0.08 & 3.57 & 0 \\
\hline
\end{tabular}

Our second measure captures the extreme values of the forecast errors, i.e. those that exceed a particular treshhold. It measures the capacity of a rule to avoid extreme inaccuracies (and thus extreme losses). We will call it extreme accuracy and we define it as follows: .

$$
F_{i, t}=\left\{\begin{array}{cc}
D-A_{i, t}, & \text { if } D>A_{i, t} \\
0, & \text { if } D \leq A_{i, t}
\end{array}\right.
$$

where $D$ is a threshold.

In table 5 we represent the two measures of accuracy of the forecasting rules. These were computed as the average of $A_{i, t}$ and $F_{i, t}$ respectively obtained from running 100 simulations of 10000 periods. We set $\beta=0.9$. For different values of $\beta$ results are qualitatively the same.

It can be seen that both measures of accuracy of the fundamentalists' forecasting rule decrease with increasing $\gamma$. Conversely, both measures of accuracy of the chartists rule are unaffected by increasing $\gamma$. This implies that under high $\gamma$ regime, i.e. when agents revise their forecasting rules very frequently the accuracy of the fundamentalists forecasting rules deteriorates significantly. This result is related to the increasing disconnection of the volatility of the exchange rate from the fundamenal variability and the increasing frequency of bubbles and crashes when $\gamma$ increases.

An interesting issue is how the proftis of these different types of agents evolve with increasing $\gamma$. In table 6 we represent the profits of chartists and fundamentalists for different values of $\gamma^{18}$. These are obtained in the same way as in table 5, i.e. as averages computed from 100 simulation runs of 10000 periods. As before $\beta=0.9$. The results are not affected by changing $\beta$.

The remarkable result is that as $\gamma$ increases the profits made by chartists increase significantly while the profits of the fundamentalists decline. The gains of the chartists outweight the losses of the fundamentalists, and this is increasingly the case as $\gamma$ increases. Thus in an environment characterised by frequent occurrencies of bubbles and crashes total market profits are high. Put differently, in an environment in which agents frequently revise their forecasting rules bubbles and crashes will occur frequently. In such a noisy environment, chartists make large profits and fundamentalists make large losses. The result of all this

\footnotetext{
${ }^{18}$ Note that the fundamentalists' profits are net of the fixed costs of collecting information $\mathrm{C}$, which was set equal to 0.05 in the simulations reported here.
} 
Table 6: Profit as a function of gamma

\begin{tabular}{|c|c|c|c|}
\hline$\gamma$ & chartists profits & fund. profits & total profits \\
\hline 0.01 & 0.03 & -0.03 & 0.00 \\
\hline 0.1 & 0.04 & -0.03 & 0.01 \\
\hline 1 & 0.07 & -0.04 & 0.03 \\
\hline 5 & 0.12 & -0.06 & 0.06 \\
\hline 10 & 0.12 & -0.06 & 0.06 \\
\hline
\end{tabular}

is that as $\gamma$ increases, the the chartists increasingly dominate the market. For sufficiently high values of $\gamma$ the chartists' weight converges to 1 and the fundamentalists tend to disappear from the market. We show this feature in figure 17 where we plot the weight of the chartists as a function of the rate of revision $\gamma$. Thus in an environment in which agents quickly revise their forecasting rules, chartists will thrive and will dominate the market. In such an environment it is quite rational to be a chartist. Next, we analyse how frequently technical traders

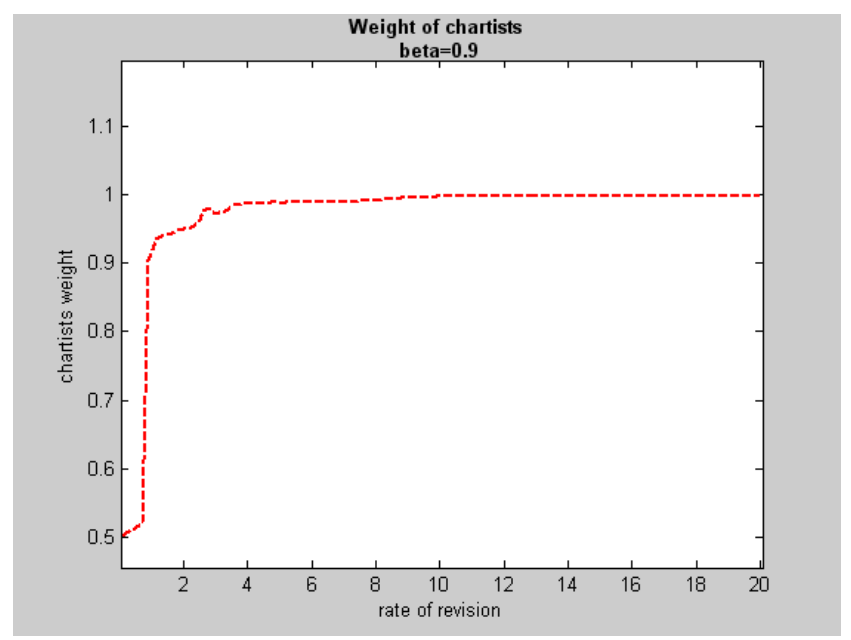

Figure 17:

anf fundamentalists make large profits and losses that exceed a particular treshhold. In order to do so, we proceed as follows. First, we compute profits and losses. Second, we consider only profits and losses that are larger than a certain threshold that we set equal to 1.5 . Third, we compute how many times large profits and losses occur. The results are summarised in table7 for $\beta=0.9$.

For low values of $\gamma$ both chartists and fundamentalists never face large losses and never make large profits. However, for increasing values of $\gamma$ agents differ greatly in their ability to make exceptionally large profits and losses. For values of $\gamma>1$, fundamentalists make large losses more frequently than chartists. For 
Table 7: Percentage of periods of large profits and large losses as a function of gamma (in percent)

\begin{tabular}{|c|c|c|c|c|}
\hline$\gamma$ & \multicolumn{2}{|c|}{ Profits $>\mathbf{1 . 5}$} & \multicolumn{2}{c|}{ Losses $<\mathbf{- 1 . 5}$} \\
\hline & chartists & fundamentalists & chartists & fundamentalists \\
\hline 0.001 & 0.001 & 0 & 0 & 0 \\
\hline 0.01 & 0 & 0 & 0 & 0 \\
\hline 0.1 & 0.03 & 0 & 0 & 0 \\
\hline 1 & 0.01 & 0.01 & 0 & 0 \\
\hline 1.5 & 0.13 & 0 & 0 & 0.14 \\
\hline 5 & 0.13 & 0 & 0 & 0.14 \\
\hline 10 & 0.14 & 0 & 0 & 0.15 \\
\hline
\end{tabular}

example, for $\gamma=10$ they make large losses, approximately, $0.15 \%$ of the time. Conversely chartists never face such large losses for any value of $\gamma$. Instead when $\gamma$ is large, chartists make exceptionally large profits more frequently than fundamentalists. This asymmetry is related to the occurrence of bubbles. As we have seen, when $\gamma$ is high, bubbles occur more frequently. This is when chartists can make exceptionally large profits, while fundamentalists then make very large losses. When the bubble crashes, chartists make losses, however, these remain limited as the chartists quickly ride on the downward trend in the market. The interesting feature of this result is that, in contrast to fundamentalist rules, chartism is a forecasting rule that has an built-in insurance against large losses. This is also one of the reasons why it tends to dominate in the market.

\section{Conclusion}

Bubbles and crashes in financial markets in general, and in the foreign exchange markets in particular, have occurred frequently, often with devastating effects. In this paper we provide a framework for analysing the emergence and the subsequent disappearance of bubbles in the foreign exchange market. We use a very simple model in which agents use an optimal portfolio in the meanvariance utility framework. The special feature of our model is that individual agents recognize that they are not capable of understanding and processing the complex information structure of the underlying model. As a result, they use simple rules to forecast the exchange rates. None of these rules is rational in the technical sense. Yet we claim that these agents act rationally within the context of the uncertainty they face. That is, agents check the 'fitness' (profitability) of the forecasting rule at each point in time and decide to reject the rule if it is less profitable (in a risk adjusted sense) than competing rules. Our model is in the tradition of evolutionary dynamics where agents use trial and error strategies. We assume that some of the forecasting rules are based on extrapolating past exchange rate movements (chartism) and others are based on mean reversion towards the fundamental rate. 
The model generates two types of equilibria. The first one, which we called a fundamental equilibrium, is one in which the exchange rate converges to its fundamental value. The exchange rate, however, can also converge to a second type of equilibrium, which we called a bubble equilibrium, and which is reached in a self-fulfilling manner. An important feature of the bubble equilibrium is that chartism (extrapolative forecasting) takes over most of the market. We simulated the model in a stochastic environment and generated complex scenarios of bubbles and crashes. One interesting aspect of the model is that it explains both the emergence of the bubble and its subsequent crash.

We also analysed under what conditions bubbles and crashes occur. We find that when agents react quickly to changing relative profitabilities of the different forecasting rules, the frequency of bubbles increases. We also find that in this case the exchange rate dynamics is very complex and produces features such as fat tails, excess kurtosis and excess volatility; features that are also found in reality. In such an environment chartists will make large profits and will tend to dominate the market, crowding out fundamentalists which have a poor forecasting record and make losses. It will then be quite rational to be a chartist.

We also found an asymmetry in the profits and losses of chartists and fundamentalists When agents revise their rules frequently then fundamentalists make large losses more frequently than chartists, while chartists make large profits more frequently than fundamentalists. This asymmetry is related to the occurrence of bubbles, which are sources of large profits for chartists using extrapolating forecasting rules and large losses for fundamentalists. The interesting feature of this result is that, in contrast to fundamentalist rules, chartism is a forecasting rule that has an built-in insurance against large losses. This is also one of the reasons why it tends to dominate in the market.

We found that bubbles are more likely to emerge when the variance of the noise is high relative to the variance of the fundamental variable. Thus, policies that lead to less variability of the underlying fundamentals (e.g. inflation) do not necessarily reduce the probability of bubbles.

We also concluded that the frequency with which bubbles occur depends in a significant way on how the fundamentalists perceive the risk of taking a contrarian position when a bubble develops. When the fundamentalists' risk aversion is independent of the degree of misalignment bubbles will occur frequently. When, however, fundamentlists becomes less risk avert as the bubble develops, these bubbles will be less frequent.

Finally we tested our model in the sense that we reproduced the statistical properties of exchange rate changes observed in reality, i.e. excess volatility, excess kurtosis, fat tails. Invariably we find that the parameter values that best mimick these properties are also those that produce significant probabilities of bubbles and crashes. 


\section{References}

Anderson, S., de Palma, A., Thisse, J.-F., 1992, Discrete Choice Theory of Product Differentiation, MIT Press, Cambridge, Mass.

Bacchetta, P. and van Wincoop E., 2003, Can information heterogeneity explain the exchange rate determination puzzle?, NBER working paper 9498.

Baxter, M., Stockman, 1989, A., "Business Cycles and the Exchange Rate Regime. Some International Evidence", Journal of Monetary Economics, 23, may 377-400.

Blanchard ,O.J., 1979, " Speculative bubbles, crashes and rational expectations", Economics Letters, 3, 387-389.

Blanchard, O.J., and Watson, M.W., 1982, "Bubbles, rational expectations and speculative markets", in Wachtel, P., eds., Crisis in economic and financial stucture: bubbles, bursts, and shocks. Lexington books: Lexington.

Brock, W., and Hommes, C., 1997, A Rational Route to Randomness, Econometrica, 65, 1059-1095

Brock, W., and Hommes, C.,1998, Heterogeneous beliefs and routes to chaos in a simple asset pricing model, Journal of Economic Dynamics and Control, $22,1235-1274$.

Cheung Y. and Lai K., 2000. " On the purchasing power parity puzzle". Journal of International Economics, 52 .

Cheung Y., Lai K. and Bergman M., 2001, " Dissecting the PPP puzzle: the unconventional roles of nominal exchange rate and price adjustments". Paper presented at CES-Ifo Conference Munich 2002.

Chiarella, C., Dieci, R., Gardini, 2002, L., "Speculative behaviour and complex asset price dynamics", Journal of Economic Behaviour and Organisation.

Copeland, L., 2000, Exchange Rates and International Finance, 3rd ed., Prentice Hall.

De Grauwe, P., Dewachter, H., and Embrechts, 1993, M., Exchange Rate Theories. Chaotic Models of the Foreign Exchange Markets, Blackwell.

De Grauwe, P., and Grimaldi, M., Exchange Rate Puzzles. 2003, A Tale of Switching Attractors, paper presented at the EEA Meeting, Stockholm, 2003

de Vries, C., 2000, "Fat tails and the history of the guilder", Tinbergen Magazine, 4, Fall, pp. 3-6.

De Long, J., Bradford, B., Schleiffer and Summers, L., 1990, "Noise Trader Risk in Financial Markets", Journal of Political Economy.

Dornbusch R., 1976, "Expectations and exchange rate dynamics", Journal of Political Economy 84.

Engel C., 2000, " Long run PPP may not hold after all", Journal of International Economics, 57.

Engel C. and Morley J., 2001, "The adjustment of prices and the adjustment of the exchange rate", Discussion paper, Department of Economics, University of Wisconsin.

Evans, M., and Lyons, R., 1999, "Order Flow and Exchange Rate Dynamics", NBER Working Paper, no. 7317. 
Evans, G., and Honkapohja, S., 2001, Learning and Expectations in Macroeconomics, Princeton University Press.

Faust, J., Rogers, J., Swanson, E., and Wright, J., 2002, Identifying the effects of monetary policy shocks on exchange rates using high-frequency data, Board of Governors of the Federal Reserve System, International Finance Discussion Paper, no. 739, October.

Flood, R, and Rose, A., 1995, "Fixing the Exchange Rate Regime: A virtual Quest for Fundamentals", Journal of Monetary Economics, 36, August, 3-37.

Frankel, J., and Froot, K., 1986, "The Dollar as a Speculative Bubble: A Tale of Fundamentalists and Chartists", NBER Working Paper, no. 1963.

Garber,P.M., 2000, "Famous first bubbles", MIT press.

Goodhart, C., 1989, "News and the Foreign Exchange Market", LSE Financial Markets Group Discussion paper, 71.

Goodhart, C., and Figliuoli, L., 1991, "Every Minute Counts in the Foreign Exchange Markets", Journal of International Money and Finance, 10, 23-52.

Guillaume D., 1996 "Chaos, randomness and order in the foreign exchange markets" PhD Thesis K.U.Leuven

Hallwood, P., MacDonald, R., 1994, International Money and Finance, 2nd ed., Blackwell, Oxford.

Huisman, R., Koedijk, K., Kool, C., and Palm, F., 2002, The tail-fatness of FX returns reconsidered, in DE Economist, 150, no. 3, September, 299-312.

Isard, P., 1995, Exchange Rate Economics, Cambridge University Press.

Johansen, S., 1991, Estimation and Hypothesis Testing of Cointegration Vectors in Gaussian Vector Autoregressive Models, Econometrica, 55, 1551-80.

Kandel,E. and Pearson, N.D., 1995, "Differential interpretation of public signals and trade in speculative markets", Journal of political Economy, 4, 831872 .

Kilian L. and M. Taylor, 2001, "Why is it So Difficult to Beat the Random Walk Forecast of Exchange Rates?" Mimeo, University of Warwick, pp. 29.

Kindleberger, C,. Manias, Panics, and Crashes. A History of Financial Crises. 1978, John Wiley \& Sons, New York, 263 pages.

Kurz, M., 1994, "On the Structure and Diversity of Rational Beliefs", Economic Theory, 4, 877-900.

Kurz, M., and Motolese, M., 2000, "Endogenous Uncertainty and Market Volatility", mimeo, Stanford University.

LI K., 1999, "Testing symmetry and proportionality in PPP : A panel data approach", Journal of Business and Economic Statistics 17 (4), 409-418.

Lux T., 1998, "The socio-economic dynamics of speculative markets: interacting agents, chaos, and fat tails of return distributions", Journal of Economic Behaviour and Organisation, vol.33.

Lux T., Marchesi M., 2000, "Volatility clustering in financial markets: a microsimulation of interacting agents", International Journal of Theoretical and Applied Finance.

Lux T., Sornette D., 2002, "On rational bubbles and fat tails", Journal of Money, Credit and Banking, 34, No 3, pp 589-610. 
Lyons, R., 2001, The Microstructure Approach to Exchange Rates, MIT Press, Cambridge, Mass.

Mandelbrot, B., 1963, The variation of certain speculative prices, The Journal of Business, University of Chicago, 36, 394-419.

Mandelbrot, B., 1997, Fractals and Scaling in Finance, Springer Verlag, 551 pages.

Meese, R., and Rogoff, 1983, "Empirical Exchange Rate Models of the Seventies: Do they Fit Out of Sample?", Journal of International Economics, 14, $3-24$.

Obstfeld, M. and Rogoff, K., 1996, Foundations of International Macroeconomics, MIT Press, Cambridge, Mass.

Obstfeld, M., and Rogoff, K., 2000, "The Six Major Puzzles in International Macroeconomics: Is there a Common Cause?", NBER Working Paper no. 7777, July.

Rogoff, K., 1996, "The purchasing power parity puzzle", Journal of Economic Literature, 34, June, 647-668.

Shiller, R., 2000, Irrational Exuberance, Princeton University Press,

Schittenkopf C., Dorffner G., Dockner E.,2001, "On nonlinear, stochastic dynamics in economics and financial time series", Studies in Nonlinear Dynamics and Econometrics 4(3), pp. 101-121.

Schleiffer, A., 2000, Introduction to Behavioural Finance, Clarendon Press.

Sornette, D., 2003, Why Stock Markets Crash, Princeton University Press.

Taylor, M., and Allen, H., 1992, "The Use of Technical Analysis in the Foreign Exchange Market", Journal of International Money and Finance, 11, $304-14$.

Thaler, R., 1994, Quasi Rational Economics, Russell Sage Foundation, New York.

Wei Shang-Jin and Kim Jungshik 1997. "The big players in the foreign exchange market:do they trade on information or noise?". NBER working paper 6256 .

Williamson, J., 1985, "The Exchange Rate System", Policy Analyses in International Economics, 5, Institute for International Economics, Washington, D.C. 


\section{A Fixed attractors and fundamental shocks: ad- ditional results}

In this appendix we present additional simulations of the effect of shocks in the fundamental on the exchange rate. We assume different values of the initial conditions. The results are shown in figures 18, 19and 20. When the initial condition (noise) is small (figure A1) no bubble equilibria exist and the exchange rate always coincides with its fundamental value. When the initial condition is gradually increased (figures A2 and A3) the range of bubble equilibria progressively increases.

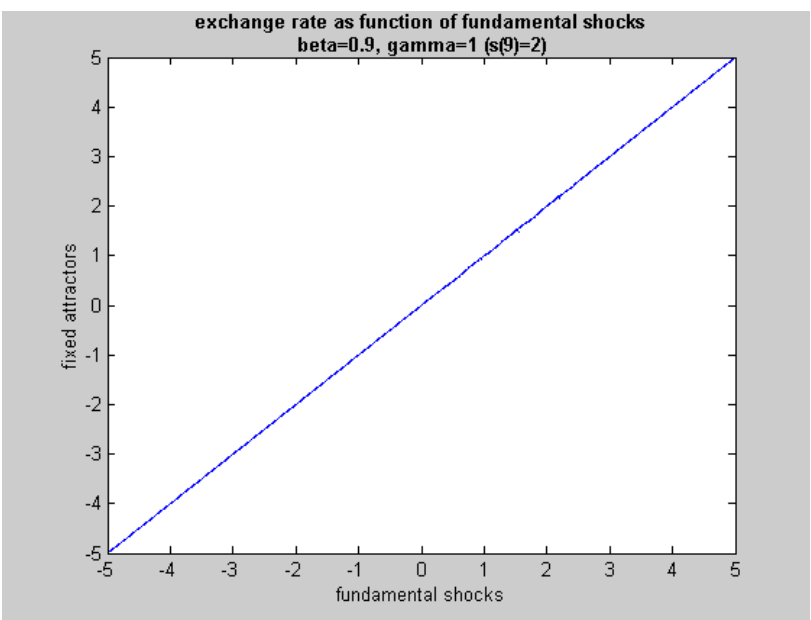

Figure 18: 


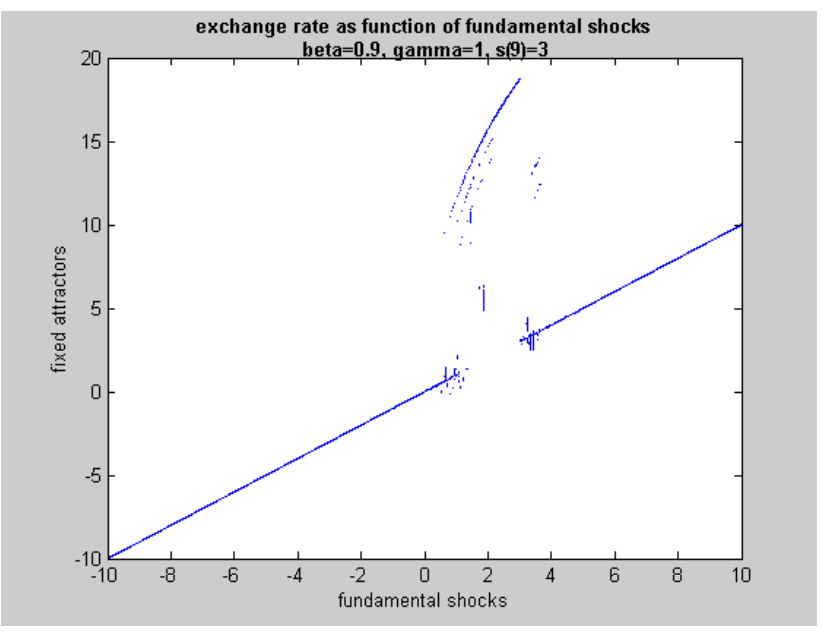

Figure 19:

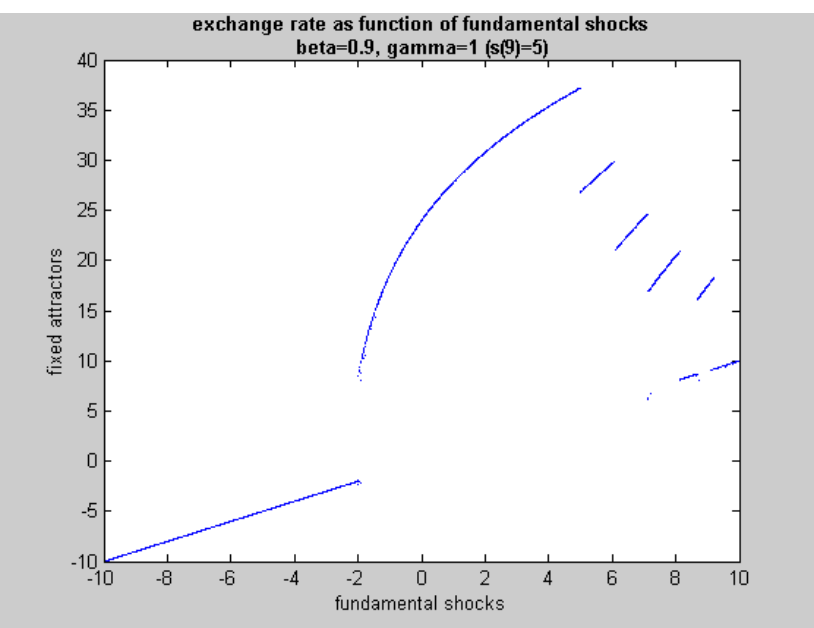

Figure 20: 


\section{B Causality tests between exchange rate and chartist weight}

In this appendix we present the results of causality tests between the exchange rate and the weight of chartists during a bubble and crash episode. We simulated the model using the standard set of parameters, and we selected an episode during which a bubble and crash occurred. We show such an episode in figure A2. A visual inspection of the graph reveals that the exchange rate appears to lead the chartist weight. at least when the bubble starts and later when the bubble bursts. Note also that the crash occurs faster than the bubble phase, a feature we often find in our simulated bubbles and crashes. This has also been found in empirical data (see Sornette(2003))

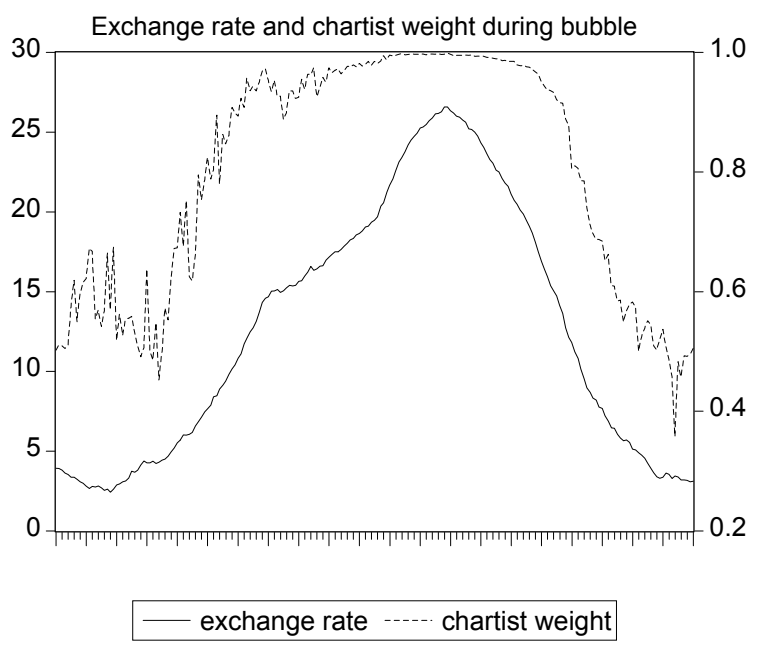

Next we performed a Granger causality test on the exchange rate and the chartist weight during the bubble and crash episode represented in figure $\mathrm{A} 2^{19}$. The result of this causality test is presented in table A1. We observe that we cannot reject the hypothesis that the exchange rate leads the chartists' weight during the bubble and crash episode, while we can reject the reverse. We find this feature in most bubble and crash episodes.

\footnotetext{
${ }^{19}$ We checked for stationarity and could not reject that the two series are stationary during the sample period.
} 
Table 8: Granger causality tests

\begin{tabular}{|c|c|c|}
\hline Null Hypothesis: & F-statistic & Probability \\
\hline cw not Granger cause exchange rate & 0.377 & 0.865 \\
\hline exchange rate not Granger cause cw & 6.85 & $6.4 \mathrm{E}-06$ \\
\hline
\end{tabular}

Note: obs $=211$, lags $=5$. 


\section{Stylised Facts of JPY-DEM Exchange Rate}

The up left panel shows the distribution of the JPY-DEM returns. The bottom left panel represents the distribution of our simulated returns. The right panels show the distribution of normally distributed exchange rate returns.
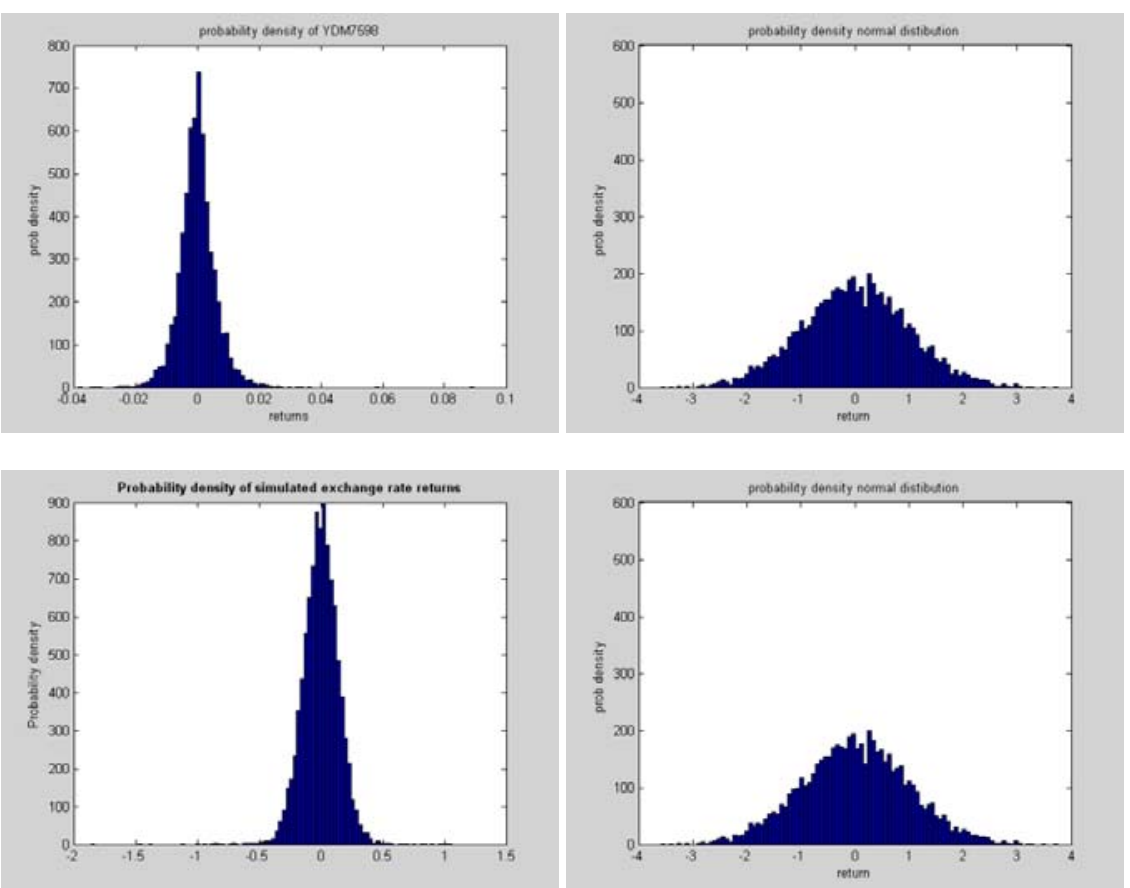


\section{CESifo Working Paper Series}

(for full list see www.cesifo.de)

980 Vivek Ghosal, Firm and Establishment Volatility: The Role of Sunk Costs, Profit Uncertainty and Technological Change, July 2003

981 Christopher A. Pissarides, Unemployment in Britain: A European Success Story, July 2003

982 Wolfgang Buchholz, Richard Cornes, and Wolfgang Peters, On the Frequency of Interior Cournot-Nash Equilibria in a Public Good Economy, July 2003

983 Syed M. Ahsan and Panagiotis Tsigaris, Choice of Tax Base Revisited: Cash Flow vs. Prepayment Approaches to Consumption Taxation, July 2003

984 Campbell Leith and Jim Malley, A Sectoral Analysis of Price-Setting Behavior in US Manufacturing Industries, July 2003

985 Hyun Park and Apostolis Philippopoulos, Choosing Club Membership under Tax Competition and Free Riding, July 2003

986 Federico Etro, Globalization and Political Geography, July 2003

987 Dan Ariely, Axel Ockenfels and Alvin E. Roth, An Experimental Analysis of Ending Rules in Internet Auctions, July 2003

988 Paola Conconi and Carlo Perroni, Self-Enforcing International Agreements and Domestic Policy Credibility, July 2003

989 Charles B. Blankart and Christian Kirchner, The Deadlock of the EU Budget: An Economic Analysis of Ways In and Ways Out, July 2003

990 M. Hasham Pesaran and Allan Timmermann, Small Sample Properties of Forecasts from Autoregressive Models under Structural Breaks, July 2003

991 Hyun Park, Apostolis Philippopoulos and Vangelis Vassilatos, On the Optimal Size of Public Sector under Rent-Seeking competition from State Coffers, July 2003

992 Axel Ockenfels and Alvin E. Roth, Late and Multiple Bidding in Second Price Internet Auctions: Theory and Evidence Concerning Different Rules for Ending an Auction, July 2003

993 Pierre Salmon, The Assignment of Powers in an Open-ended European Union, July 2003

994 Louis N. Christofides and Chen Peng, Contract Duration and Indexation in a Period of Real and Nominal Uncertainty, July 2003 
995 M. Hashem Pesaran, Til Schuermann, Björn-Jakob Treutler, and Scott M. Weiner, Macroeconomic Dynamics and Credit Risk: A Global Perspective, July 2003

996 Massimo Bordignon and Sandro Brusco, On Enhanced Cooperation, July 2003

997 David F. Bradford, Addressing the Transfer-Pricing Problem in an Origin-Basis X Tax, July 2003

998 Daniel Gros, Who Needs Foreign Banks?, July 2003

999 Wolfram Merzyn and Heinrich W. Ursprung, Voter Support for Privatizing Education: Evidence on Self-Interest and Ideology, July 2003

1000 Jo Thori Lind, Fractionalization and the Size of Government, July 2003

1001 Daniel Friedman and Donald Wittman, Litigation with Symmetric Bargaining and TwoSided Incomplete Information, July 2003

1002 Matthew Clarke and Sardar M. N. Islam, Health Adjusted GDP (HAGDP) Measures of the Relationship Between Economic Growth, Health Outcomes and Social Welfare, July 2003

1003 Volker Grossmann, Contest for Attention in a Quality-Ladder Model of Endogenous Growth, August 2003

1004 Marcel Gérard and Joan Martens Weiner, Cross-Border Loss Offset and Formulary Apportionment: How do they affect multijurisdictional firm investment spending and interjurisdictional tax competition?, August 2003

1005 Burkhard Heer, Nonsuperneutrality of Money in the Sidrauski Model with Heterogeous Agents, August 2003

1006 V. Anton Muscatelli, Piergiovanna Natale, and Patrizio Tirelli, A Simple and Flexible Alternative to the Stability and Growth Pact Deficit Ceilings. Is it at hand?, August 2003

1007 Reto Foellmi and Josef Zweimüller, Inequality and Economic Growth: European Versus U.S. Experiences, August 2003

1008 James S. Costain and Michael Reiter, Business Cycles, Unemployment Insurance, and the Calibration of Matching Models, August 2003

1009 Marco Runkel, Optimal Contest Design when the Designer's Payoff Depends on Competitive Balance, August 2003

1010 Donald O. Parsons, Torben Tranaes and Helene Bie Lilleør, Voluntary Public Unemployment Insurance, August 2003

1011 Rüdiger Pethig and Andreas Wagener, Profit Tax Competition and Formula Apportionment, August 2003 
1012 Johan Willner, Privatisation and Public Ownership in Finland, August 2003

1013 Seppo Kari and Jouko Ylä-Liedenpohja, Taxation and Valuation of International Real Investments, August 2003

1014 James Heckman, Rosa Matzkin and Lars Nesheim, Simulation and Estimation of Hedonic Models, August 2003

1015 Biswa N. Bhattacharyay, Towards a Macro-Prudential Leading Indicators Framework for Monitoring Financial Vulnerability, August 2003

1016 J. Stephen Ferris and Stanley L. Winer, Searching for Keynes: With Application to Canada, 1870-2000, August 2003

1017 Massimo Bordignon, Luca Colombo and Umberto Galmarini, Fiscal Federalism and Endogenous Lobbies’ Formation, August 2003

1018 Annette Alstadsæter, The Dual Income Tax and Firms' Income Shifting through the Choice of Organizational Form and Real Capital Investments, August 2003

1019 Peter Fredriksson and Bertil Holmlund, Optimal Unemployment Insurance Design: Time Limits, Monitoring, or Workfare?, August 2003

1020 Kashif S. Mansori, Following in their Footsteps: Comparing Interest Parity Conditions in Central European Economies to the Euro Countries, August 2003

1021 Christoph Borgmann and Matthias Heidler, Demographics and Volatile Social Security Wealth: Political Risks of Benefit Rule Changes in Germany, August 2003

1022 Kjell Erik Lommerud, Bjørn Sandvik and Odd Rune Staume, Good Jobs, Bad Jobs and Redistribution, August 2003

1023 Patrick Karl O’Brien, The Governance of Globalization: The Political Economy of Anglo-American Hegemony, 1793-2003, September 2003

1024 Antonio Ciccone and Giovanni Peri, Skills’ Substitutability and Technological Progress: U.S. States 1950-1990, September 2003

1025 Bjørn Sandvik, Optimal Taxation and Normalisations, September 2003

1026 Massimo Bordignon and Gilberto Turati, Bailing Out Expectations and Health Expenditure in Italy, September 2003

1027 José A. Herce, Namkee Ahn, Ricard Génova, and Joaquín Pereira, Bio-Demographic and Health Aspects of Ageing in the EU, September 2003

1028 John Komlos and Marieluise Baur, From the Tallest to (One of) the Fattest: The Enigmatic Fate of the American Population in the $20^{\text {th }}$ Century, September 2003 
1029 Stefan Napel and Mika Widgrén, Bargaining and Distribution of Power in the EU's Conciliation Committee, September 2003

1030 Kai Li and Dale J. Poirier, Relationship Between Maternal Behavior During Pregnancy, Birth Outcome, and Early Childhood Development: An Exploratory Study, September 2003

1031 Ivar Ekeland, James J. Heckman, and Lars Nesheim, Identifcation and Estimation of Hedonic Models, September 2003

1032 Kjetil Bjorvatn and Alexander W. Cappelen, Decentralization and the Fate of Minorities, September 2003

1033 Lars-Erik Borge and Jørn Rattsø, The Relationships Between Costs and User Charges: The Case of a Norwegian Utility Service, September 2003

1034 Maureen Were and Nancy N. Nafula, An Assessment of the Impact of HIV/AIDS on Economic Growth: The Case of Kenya, September 2003

1035 A. Lans Bovenberg, Tax Policy and Labor Market Performance, September 2003

1036 Peter Birch Sørensen, Neutral Taxation of Shareholder Income: A Norwegian Tax Reform Proposal, September 2003

1037 Roberta Dessi and Sheilagh Ogilvie, Social Capital and Collusion: The Case of Merchant Guilds, September 2003

1038 Alessandra Casarico and Carlo Devillanova, Capital-skill Complementarity and the Redistributive Effects of Social Security Reform, September 2003

1039 Assaf Razin and Efraim Sadka, Privatizing Social Security Under Balanced-Budget Constraints: A Political-Economy Approach, September 2003

1040 Michele Moretto, Paolo M. Panteghini, and Carlo Scarpa, Investment Size and Firm’s Value under Profit Sharing Regulation, September 2003

1041 A. Lans Bovenberg and Peter Birch Sørensen, Improving the Equity-Efficiency Tradeoff: Mandatory Savings Accounts for Social Insurance, September 2003

1042 Bas van Aarle, Harry Garretsen, and Florence Huart, Transatlantic Monetary and Fiscal Policy Interaction, September 2003

1043 Jerome L. Stein, Stochastic Optimal Control Modeling of Debt Crises, September 2003

1044 Thomas Stratmann, Tainted Money? Contribution Limits and the Effectiveness of Campaign Spending, September 2003

1045 Marianna Grimaldi and Paul De Grauwe, Bubbling and Crashing Exchange Rates, September 2003 